Review

\title{
Research Progress in Prognostic Factors and Biomarkers of Ovarian Cancer
}

\author{
Shuna Liu ${ }^{1,2}$, Ming $\mathrm{Wu}^{1,2}$, Fang Wang ${ }^{1,2}$ \\ 1. Department of Laboratory Medicine, the First Affiliated Hospital of Nanjing Medical University, Nanjing, China, 210029. \\ 2. National Key Clinical Department of Laboratory Medicine, Nanjing, China, 210029. \\ $\bowtie$ Corresponding author: Fang Wang, E-mail: wangfang@njmu.edu.cn, Tel./Fax: +86 2586862814. \\ (C) The author(s). This is an open access article distributed under the terms of the Creative Commons Attribution License (https://creativecommons.org/licenses/by/4.0/). \\ See http://ivyspring.com/terms for full terms and conditions.
}

Received: 2020.05.02; Accepted: 2021.04.22; Published: 2021.05.13

\begin{abstract}
Ovarian cancer is a serious threat to women's health; its early diagnosis rate is low and prone to metastasis and recurrence. The current conventional treatment for ovarian cancer is a combination of platinum and paclitaxel chemotherapy based on surgery. The recurrence and progression of ovarian cancer with poor prognosis is a major challenge in treatment. With rapid advances in technology, understanding of the molecular pathways involved in ovarian cancer recurrence and progression has increased, biomarker-guided treatment options can greatly improve the prognosis of patients. This review systematically discusses and summarizes existing and new information on prognostic factors and biomarkers of ovarian cancer, which is expected to improve the clinical management of patients and lead to effective personalized treatment.
\end{abstract}

Key words: ovarian cancer; prognostic factor; biomarker

\section{Introduction}

Ovarian cancer is the most fatal gynecological tumor, its incidence is next to cervical cancer and endometrial cancer, but its mortality rate is the first among reproductive system malignancies. According to the data of cancer statistics in 2020, the number of new cases is about 21750 and the number of deaths is 13940 [1]. Ovarian is located in the posterolateral uterine bottom, the onset is insidious, the early symptoms lack specificity, and the screening effect is limited, so the early diagnosis of ovarian cancer is difficult. According to the American congress of obstetricians and gynecologists (ACOG), 70 to 75 percent of ovarian cancers are diagnosed late, and the 5 -year survival rate for most women is 20 to 30 percent [2]. Compared with other gynecological tumors, ovarian cancer has complex pathological types, high recurrence rate and poor prognosis. Patients with distant metastasis due to delayed medical treatment and tolerance to chemotherapy have worse prognosis. Therefore, the identification of effective clinical prognostic factors and biomarkers is crucial to improve the prognosis of ovarian cancer patients. With the in-depth study of the molecular changes that drive the transformation of ovarian cancer and tumor progression, many new molecular analysis techniques have been widely used. Recent studies have shown that microRNAs (miRNAs) may play an important role in the pathogenesis of ovarian cancer and serve as potential biomarkers [3].

The main contents of this review are divided into two parts: classic prognostic factors and novel prognostic factors. Classic prognostic factors included clinicopathologic factors (FIGO stage, degree of differentiation, degree of tumor reduction surgery, course of chemotherapy) and serum CA125. New prognostic factors mainly include blood- or tissuebased biomarkers. The ovarian cancer field has lagged in incorporating targeted therapies into standard treatments, these novel biomarkers are expected to provide therapeutic targets for ovarian cancer, thus guiding clinical practice, improving patient prognosis and ultimately reducing the risk of death of ovarian cancer patients.

\section{Search Methods}

Based on the topics discussed in this review, we systematically searched the recent medical literatures on novel prognostic biomarkers of ovarian cancer in 
PubMed and PMC databases by using our search strategy. All the literatures included in the study were published between February 1, 2015 and February 1, 2021. After excluding the duplicated literatures in the two databases, a total of 1,923 literatures met the restriction conditions. Then the retrieved literatures were imported into the literature management software Endnote. Preliminary screening was performed by reading the titles and abstracts of the literatures to exclude irrelevant studies, and then the full text of the included literatures was evaluated. In order to ensure the reliability of the research results, we only selected studies with more than 50 ovarian cancer patients, and the biomarkers studied in the literature were consistent with the clinical results. The inclusion and exclusion criteria and search strategy are provided in the appendix. Finally, a manual search was conducted in major journals and the reference lists of the selected papers to find other relevant citations that were missing by the electronic search.

\section{Search Results}

A total of 297 different novel prognostic biomarkers were reported in 296 studies that met the inclusion criteria (Figure 1). These prognostic biomarkers were classified according to the purpose of the study; there were 45 studies on biomarkers in the blood of ovarian cancer patients (Table 1) and 251 studies on biomarkers in tumor tissues (Tables 2-4).

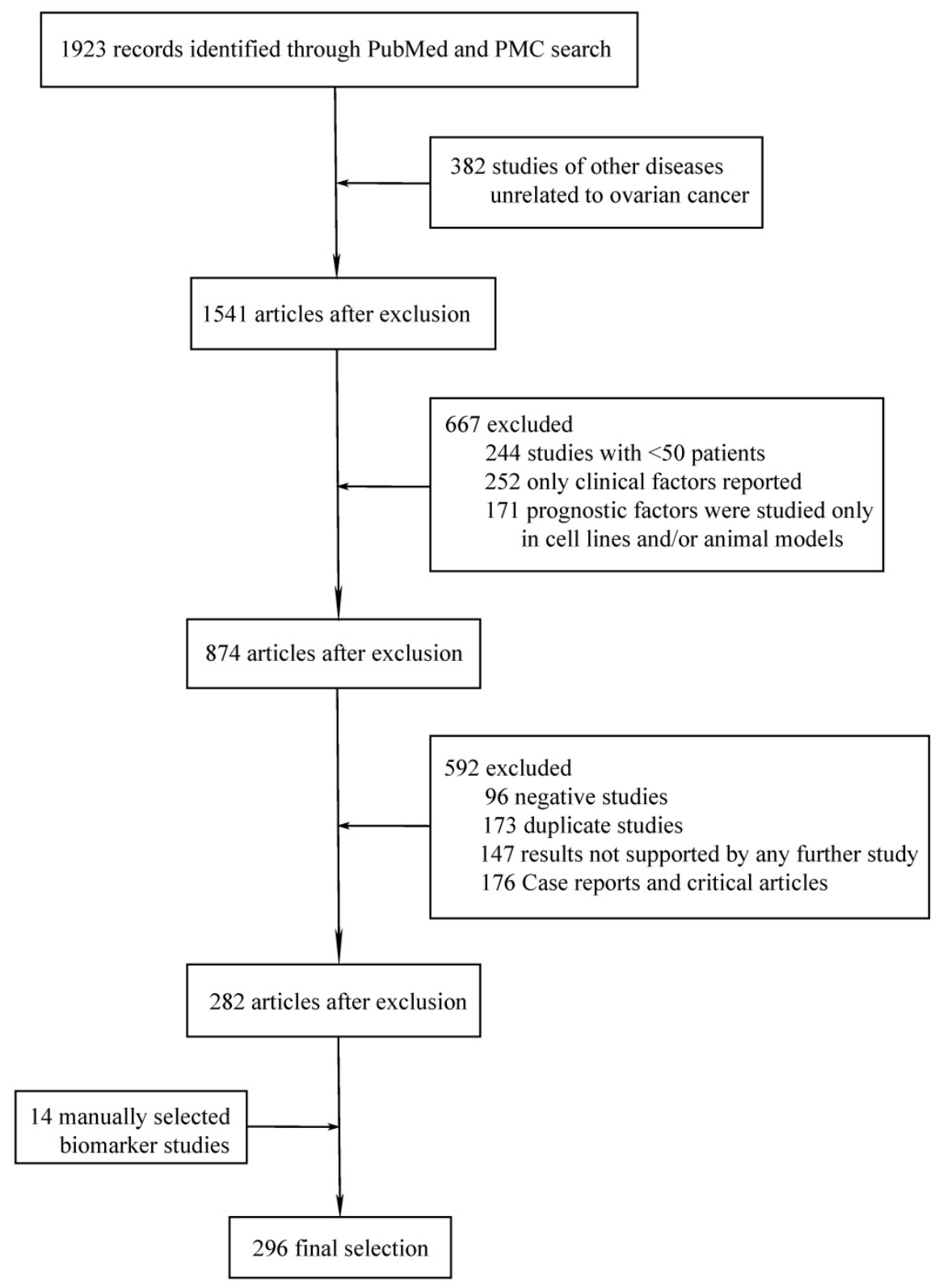

Figure 1. Flowchart of article selection process. 
Table 1. Blood-based biomarkers in ovarian cancer

\begin{tabular}{|c|c|c|c|c|c|c|}
\hline & \multirow{2}{*}{$\begin{array}{l}\text { Expression } \\
\text { or ratio }\end{array}$} & \multirow{2}{*}{$\begin{array}{l}\text { Potential clinical } \\
\text { use }\end{array}$} & \multicolumn{4}{|l|}{ Example study } \\
\hline & & & Study & Studied biomarkers & Subsite & Patients(n) \\
\hline \multicolumn{7}{|l|}{ Cell proliferation and invasion } \\
\hline Leptin & Increased & Poor prognosis & Kato, S., et al. (2015) $)^{16}$ & Leptin & EOC & 70 \\
\hline $\operatorname{miR}-429$ & Increased & Good prognosis & Meng, X., et al. (2015) ${ }^{17}$ & $\operatorname{miR}-429$ & EOC & 180 \\
\hline ADAM12 & Increased & Poor prognosis & Cheon, D. J., et al. (2015) ${ }^{18}$ & ADAM12 & HGSOC & 84 \\
\hline Septin-9, clusterin & Increased & Poor prognosis & Lyu, N., et al. $(2018)^{19}$ & Septin-9, clusterin & EOC & 137 \\
\hline MMP3, TIMP3 & Increased & Poor prognosis & Cymbaluk-Ploska, A., et al. (2018) ${ }^{20}$ & MMP3, TIMP3 & OC & 104 \\
\hline MSLN & Increased & Poor prognosis & Karolina Okla et al. $(2018)^{21}$ & MSLN & EOC & 97 \\
\hline CYFRA21-1 & Increased & Poor prognosis & Jin, C., et al. (2019) ${ }^{22}$ & CYFRA21-1 & EOC & 203 \\
\hline \multicolumn{7}{|l|}{ Inflammation } \\
\hline NLR & Increased & Poor prognosis & Feng, Z., et al. (2016) ${ }^{23}$ & NLR & HGSOC & 875 \\
\hline NLR & Increased & Poor prognosis & Li, Z., et al. (2017) ${ }^{24}$ & NLR & EOC & 654 \\
\hline $\mathrm{CRP} / \mathrm{Alb}$ & Increased & Poor prognosis & Liu, Y., et al. (2017) 25 & $\mathrm{CRP} / \mathrm{Alb}$ & OC & 200 \\
\hline NLR, LDH & Increased & Poor prognosis & Mauricio, P., et al. $(2018)^{26}$ & NLR, LDH & HGSOC & 128 \\
\hline AFR & Decreased & Poor prognosis & Yu, W., et al. (2019)27 & AFR & EOC & 313 \\
\hline NLR & Increased & Poor prognosis & Ceran, M. U., et al. (2019) ${ }^{28}$ & NLR & EOC & 244 \\
\hline PLR & Increased & Poor prognosis & Ceran, M. U., et al. (2019) ${ }^{28}$ & PLR & EOC & 244 \\
\hline NLR & Increased & Poor prognosis & Nomelini, R. S., et al. (2019) ${ }^{29}$ & NLR & OC & 72 \\
\hline \multicolumn{7}{|l|}{ Angiogenesis } \\
\hline Fibulin-4 & Increased & Good prognosis & Chen, J., et al. (2015) 30 & Fibulin-4 & OC & 160 \\
\hline VEGF & Increased & Poor prognosis & Dobrzycka, B., et al. (2015) & VEGF & SOC & 92 \\
\hline VEGF-A & Increased & Good prognosis & Komatsu, H., et al. (2017) ${ }^{32}$ & VEGF-A & $\mathrm{EOC}$ & 128 \\
\hline LncRNA MALAT1 & Increased & Poor prognosis & Qiu, J. J., et al. (2018) 33 & LncRNA MALAT1 & $\mathrm{EOC}$ & 60 \\
\hline \multicolumn{7}{|l|}{ Antioxidant } \\
\hline 8-OHdG & Increased & Poor prognosis & Pylväs-Eerola, M., et al. (2015) ${ }^{34}$ & 8-OHdG & EOC & 112 \\
\hline \multicolumn{7}{|l|}{ Immune response } \\
\hline $\mathrm{TNFa} / \mathrm{IL}-4$ ratio & Increased & Good prognosis & Hao, C. J., et al. (2016) 35 & TNFa/IL-4 ratio & OC & 50 \\
\hline sPD-L1 & Increased & Poor prognosis & Chatterjee, J., et al. (2017) ${ }^{36}$ & sPD-L1 & EOC & 71 \\
\hline s-CD95L & Increased & Good prognosis & De La Motte Rouge, T., et al. (2019) ${ }^{37}$ & s-CD95L & HGSOC & 51 \\
\hline absolute lymphocyte count & Decreased & Poor prognosis & Lee, Y. J., et al. (2019) 38 & absolute lymphocyte count & OC & 537 \\
\hline CD4/CD8 ratio & Decreased & Good prognosis & Waki, K., et al. (2020) ${ }^{39}$ & CD4/CD8 ratio & OC & 52 \\
\hline \multicolumn{7}{|l|}{ Chemotherapeutic sensitivity } \\
\hline $\begin{array}{l}\text { CEBPA, C.69.OG }>\mathrm{T} \\
\text { polymorphism (rs34529039) }\end{array}$ & Increased & Poor prognosis & Konopka, B., et al. (2016) 40 & $\begin{array}{l}\text { CEBPA, C.69.OG>T } \\
\text { polymorphism (rs34529039) }\end{array}$ & $\mathrm{OC}$ & 118 \\
\hline hyperfibrinogenemia & Increased & Poor prognosis & Feng, Z., et al. (2016) ${ }^{41}$ & hyperfibrinogenemia & HGSOC & 875 \\
\hline ERCC1 & Expression & Poor prognosis & Chebouti, I., et al. (2017) ${ }^{42}$ & ERCC1 & OC & 65 \\
\hline miR-135a-3p & Increased & Good prognosis & Fukagawa, S., et al. (2017) ${ }^{43}$ & miR-135a-3p & OC & 98 \\
\hline Gal-8, Gal-9 & Increased & Poor prognosis & Labrie, M., et al. (2017) & Gal-8, Gal-9 & HGSOC & 160 \\
\hline \multicolumn{7}{|l|}{ Mitotic process } \\
\hline Aurora A codon 57 SNP & Increased & Good prognosis & Niu, H., et al. (2017) ${ }^{45}$ & Aurora A codon 57 SNP & OC & 122 \\
\hline \multicolumn{7}{|l|}{ EMT and metastasis } \\
\hline miR 200a, miR 200b, miR 200c & Increased & Poor prognosis & Zuberi, M., et al. (2015) ${ }^{46}$ & $\operatorname{miR} 200 a$, miR 200b, miR 200c & $\mathrm{EOC}$ & 70 \\
\hline miR-200b, miR-200c & Increased & Poor prognosis & Meng, X., et al. (2016) ${ }^{47}$ & miR-200b, miR-200c & EOC & 163 \\
\hline \multicolumn{7}{|c|}{ Deregulation of the cellular transport } \\
\hline KPNA2 & Increased & Poor prognosis & Huang, L., et al. (2017) $)^{48}$ & KPNA2 & EOC & 162 \\
\hline \multicolumn{7}{|l|}{ Apoptosis process } \\
\hline survivin & Increased & Poor prognosis & Dobrzycka, B., et al. (2015) $)^{31}$ & survivin & SOC & 92 \\
\hline Smac/DIABLO & Decreased & Poor prognosis & Dobrzycka, B., et al. (2015) $)^{31}$ & Smac/DIABLO & SOC & 92 \\
\hline \multicolumn{7}{|l|}{ Others } \\
\hline miR-200c, miR-141 & Increased & Good prognosis & Gao, Y.C., et al. (2015) ${ }^{49}$ & miR-200C, miR-141 & $\mathrm{EOC}$ & 93 \\
\hline Platelet counts & Increased & Poor prognosis & Chen, Y., et al. (2015)50 & Platelet counts & $\mathrm{EOC}$ & 816 \\
\hline SFRA & Increased & Poor prognosis & Kurosaki, A., et al. (2016) ${ }^{51}$ & SFRA & $\mathrm{EOC}$ & 128 \\
\hline OPN & Increased & Poor prognosis & Zivny, J. H., et al. (2016) ${ }^{52}$ & OPN & SOC & 66 \\
\hline microRNA-125b (miR-125b) & Increased & Poor prognosis & Zuberi, M., et al. (2016) 53 & microRNA-125b (miR-125b) & $\mathrm{EOC}$ & 70 \\
\hline $\operatorname{miR}-125 b$ & Increased & Good prognosis & Zhu, T., et al. (2017) 54 & $\operatorname{miR}-125 b$ & $\mathrm{EOC}$ & 135 \\
\hline BGA & Expression & Good prognosis & Montavon Sartorius, C., et al. (2018)55 & BGA & OC & 282 \\
\hline RASSF1A rs1989839C > T SNP & Increased & Poor prognosis & He, W., et al. (2018) 56 & RASSF1A rs1989839C > T SNP & $\mathrm{OC}$ & 1375 \\
\hline $\begin{array}{l}\text { MACC1 and S100A4 } \\
\text { transcripts }\end{array}$ & Increased & Poor prognosis & Link, T., et al. (2019) ${ }^{57}$ & $\begin{array}{l}\text { MACC1 and S100A4 } \\
\text { transcripts }\end{array}$ & OC & 79 \\
\hline sP (Hyp-Leu,Glu-Phe-Trp) & Decreased & Good prognosis & Lu, X., et al. (2019) $)^{58}$ & sP (Hyp-Leu,Glu-Phe-Trp) & EOC & 98 \\
\hline
\end{tabular}

Abbreviations: miR: MicroRNA; NLR: the ratio of neutrophil count to lymphocyte count; AFR: albumin-to-fibrinogen ratio; PLR: platelet lymphocyte ratio; SNP: single Nucleotide Polymorphism; MSLN: Mesothelin; AAK: Aurora A kinase; Gal: Galectin; VEGF: vascular endothelial growth factor; sPD-L1: soluble PD - L1; OC: ovarian cancer; HGSOC: High grade serous ovarian cancer; EOC: epithelial ovarian cancer. 
Table 2. Tissue-based immunohistochemistry biomarkers in ovarian cancer

\begin{tabular}{|c|c|c|c|c|c|c|}
\hline & \multirow{2}{*}{$\begin{array}{l}\text { Expression or } \\
\text { ratio }\end{array}$} & \multirow{2}{*}{$\begin{array}{l}\text { Potential clinical } \\
\text { use }\end{array}$} & \multicolumn{4}{|l|}{ Example study } \\
\hline & & & Study & Studied biomarkers & Subsite & Patients (n) \\
\hline \multicolumn{7}{|l|}{ EMT and metastasis } \\
\hline CTHRC1 & Increased & Poor prognosis & Hou, M., et al. (2015) ${ }^{59}$ & CTHRC1 & EOC & 88 \\
\hline ZEB2 & Increased & Poor prognosis & Prislei, S., et al. (2015) 60 & ZEB2 & EOC & 143 \\
\hline CD44v6 & Increased & Poor prognosis & Tjhay, F., et al. (2015)61 & CD44v6 & EOC & 59 \\
\hline miR-506 & Increased & Good prognosis & Sun, Y., et al. (2015)62 & miR-506 & EOC & 204 \\
\hline FILIP1L & Increased & Good prognosis & Kwon, M., et al. (2016)63 & FILIP1L & OC & 369 \\
\hline Par3 & Decreased & Good prognosis & Nakamura, H., et al. (2016)64 & Par3 & OC & 50 \\
\hline MMP-14, CD44 & $\begin{array}{l}\text { Double } \\
\text { expression }\end{array}$ & Poor prognosis & Vos, M. C., et al. (2016)65 & MMP-14, CD44 & $\mathrm{OC}$ & 97 \\
\hline OTUB1 & Expression & Poor prognosis & Wang, Y., et al. (2016) ${ }^{66}$ & OTUB1 & $\mathrm{OC}$ & 200 \\
\hline ESRP1 & Increased & Good prognosis & Chen, L., et al. (2017) ${ }^{67}$ & ESRP1 & EOC & 109 \\
\hline MDM2 & Increased & Good prognosis & Chen, Y., et al. (2017)68 & MDM2 & $\mathrm{OC}$ & 104 \\
\hline $\mathrm{CD} 24$ & Increased & Poor prognosis & Nakamura, K., et al. (2017) ${ }^{69}$ & CD24 & $\mathrm{OC}$ & 174 \\
\hline CCNG1 & Increased & Poor prognosis & Xu, Y., et al. (2019)70 & CCNG1 & HGSOC & 266 \\
\hline DDR2 & Increased & Poor prognosis & Ramalho, S., et al. (2019) 71 & DDR2 & HGSOC & 78 \\
\hline \multicolumn{7}{|c|}{ Inflammation and immune response } \\
\hline CD8/Treg ratio & Increased & Good prognosis & Knutson, K. L., et al. (2015) 72 & CD8/Treg ratio & EOC & 405 \\
\hline PD-1, PD-L1 & Increased & Good prognosis & Darb-Esfahani, S., et al. $(2016)^{73}$ & PD-1, PD-L1 & HGSOC & 215 \\
\hline $\begin{array}{l}\text { Tumour-infiltrating B cell } \\
\text { and plasma cell }\end{array}$ & Increased & Poor prognosis & Lundgren, S., et al. (2016) ${ }^{74}$ & $\begin{array}{l}\text { Tumour-infiltrating B } \\
\text { cell and plasma cell }\end{array}$ & EOC & 154 \\
\hline TIL & Increased & Good prognosis & James, F. R., et al. (2017)75 & TIL & EOC & 707 \\
\hline T-bet ${ }^{+}$TILs & Increased & Good prognosis & Xu, Y., et al. $(2017)^{76}$ & T-bet ${ }^{+}$TILs & EOC & 81 \\
\hline PD-L1 & Increased & Poor prognosis & Zhu, J., et al. $(2017)^{77}$ & PD-L1 & OCCC & 138 \\
\hline $\begin{array}{l}\text { Transcription factors WT1 } \\
\text { and p53 }\end{array}$ & Increased & Poor prognosis & Carter, J. H., et al. (2018) $)^{78}$ & $\begin{array}{l}\text { Transcription factors } \\
\text { WT1 and p53 }\end{array}$ & $\mathrm{OC}$ & 96 \\
\hline SOCS-1 & Increased & Poor prognosis & Nakagawa, S., et al. (2018) $)^{79}$ & SOCS-1 & OC & 83 \\
\hline PD-L1 & Increased & Good prognosis & Kim, K. H., et al. (2019) 80 & PD-L1 & EOC & 248 \\
\hline TIL & Increased & Good prognosis & Mauricio, P., et al. (2019) ${ }^{81}$ & TIL & HGSOC & 128 \\
\hline RCAS1-Ir & Increased & Poor prognosis & Szubert, S., et al. (2019) $)^{82}$ & RCAS1-Ir & EOC & 67 \\
\hline VISTA & Expression & Good prognosis & Zong, L., et al. (2020) ${ }^{83}$ & VISTA & $\mathrm{OC}$ & 146 \\
\hline $\begin{array}{l}\text { Co-expression of } \mathrm{CD}^{+} \text {and } \\
\text { granzyme } \mathrm{B}^{+}\end{array}$ & Increased & Good prognosis & Jäntti, T., et al. $(2020)^{84}$ & $\begin{array}{l}\text { Co-expression of } \mathrm{CD}^{+} \\
\text {and granzyme } \mathrm{B}^{+}\end{array}$ & HGSOC & 67 \\
\hline \multicolumn{7}{|l|}{ Antioxidant } \\
\hline Nrf2 & Expression & Poor prognosis & Liew, P. L., et al. $(2015)^{85}$ & Nrf2 & OC & 108 \\
\hline SOD2 & Increased & Poor prognosis & Amano, T., et al. (2019) 86 & SOD2 & EAOC & 61 \\
\hline \multicolumn{7}{|l|}{ Angiogenesis } \\
\hline pIKK & Expression & Poor prognosis & Kinose, Y., et al. (2015) ${ }^{87}$ & pIKK & $\mathrm{OC}$ & 94 \\
\hline PDGF $\beta R$ & Increased & Poor prognosis & Corvigno, S., et al. (2016) ${ }^{88}$ & PDGF $\beta R$ & SOC & 186 \\
\hline VEGF-R1, VEGF-R2 & Expression & Good prognosis & Skirnisdottir, I., et al. (2016) ${ }^{89}$ & VEGF-R1, VEGF-R2 & EOC & 131 \\
\hline Nestin & Increased & Poor prognosis & Onisim, A., et al. (2016) $)^{90}$ & Nestin & SOC & 85 \\
\hline MIG-7 & Increased & Poor prognosis & Huang, B., et al. (2016) ${ }^{91}$ & MIG-7 & EOC & 121 \\
\hline PTEN & Expression & Good prognosis & Shen, W., et al. $(2017)^{92}$ & PTEN & $\mathrm{OC}$ & 76 \\
\hline HIF-la and VEGF & Expression & Poor prognosis & Shen, W., et al. (2017) ${ }^{92}$ & HIF-la and VEGF & $\mathrm{OC}$ & 76 \\
\hline AEG-1 & Increased & Poor prognosis & Yu, X., et al. (2018) ${ }^{93}$ & AEG-1 & EOC & 170 \\
\hline VEGF, SEMA4D & Expression & Poor prognosis & Chen, Y., et al. (2018) ${ }^{94}$ & VEGF, SEMA4D & EOC & 124 \\
\hline TBC1D16 & Increased & Good prognosis & Yang, Z., et al. (2018) ${ }^{95}$ & TBC1D16 & EOC & 156 \\
\hline PGF & Increased & Poor prognosis & Meng, Q., et al. (2018) ${ }^{96}$ & PGF & EOC & 89 \\
\hline VEGF-A & Decreased & Poor prognosis & Sopo, M., et al. (2019)97 & VEGF-A & OC & 86 \\
\hline vasohibin-1, MACC1 & Increased & Poor prognosis & Yu, L., et al. (2019)98 & vasohibin-1, MACC1 & $\mathrm{SOC}$ & 124 \\
\hline Tie-2 & Increased & Poor prognosis & Sopo, M., et al. (2020)99 & Tie-2 & HGSOC & 86 \\
\hline \multicolumn{7}{|l|}{ Cell proliferation } \\
\hline FASN & Increased & Poor prognosis & Cai, Y., et al. (2015) 100 & FASN & $\mathrm{OC}$ & 60 \\
\hline CD73 & Increased & Poor prognosis & Turcotte, M., et al. (2015) 101 & CD73 & HGSOC & 208 \\
\hline SPINK1 & Increased & Poor prognosis & Mehner, C., et al. (2015)102 & SPINK1 & EOC & 490 \\
\hline KCNN4, S100A14 & Increased & Poor prognosis & Zhao, H., et al. (2016) & KCNN4, S100A14 & $\mathrm{SOC}$ & 127 \\
\hline EGFR & Increased & Poor prognosis & Xu, L., et al. (2016) 104 & EGFR & EOC & 67 \\
\hline Gab1 & Increased & Poor prognosis & Hu, L. and R. Liu (2016) ${ }^{105}$ & Gab1 & EOC & 124 \\
\hline IL-36a & Decreased & Poor prognosis & Chang, L., et al. (2017)106 & IL-36a & EOC & 96 \\
\hline DOT1L & Increased & Poor prognosis & Zhang, X., et al. (2017)107 & DOT1L & OC & 250 \\
\hline KRT5, KRT6 & Increased & Poor prognosis & Ricciardelli, C., et al. (2017) ${ }^{108}$ & KRT5, KRT6 & SOC & 117 \\
\hline hLSR & Increased & Poor prognosis & Hiramatsu, K., et al. (2018)109 & hLSR & EOC & 104 \\
\hline PAUF, TIR4 & $\begin{array}{l}\text { TLR4high and } \\
\text { PAUFhigh/ } \\
\text { TLR4 }{ }^{\text {high }}\end{array}$ & Poor prognosis & Choi, C. H., et al. (2018) $)^{110}$ & PAUF, TIR4 & EOC & 205 \\
\hline PCDH8 & Decreased & Poor prognosis & Cao, Y., et al. (2018) $)^{111}$ & PCDH8 & $\mathrm{OC}$ & 68 \\
\hline RIF1 & Increased & Poor prognosis & Liu, Y. B., et al. (2018) & RIF1 & EOC & 72 \\
\hline FGFR2 & Increased & Poor prognosis & Li, M., et al. (2018) ${ }^{113}$ & FGFR2 & $\mathrm{OC}$ & 426 \\
\hline
\end{tabular}




\begin{tabular}{|c|c|c|c|c|c|c|}
\hline & \multirow{2}{*}{$\begin{array}{l}\text { Expression or } \\
\text { ratio }\end{array}$} & \multirow{2}{*}{$\begin{array}{l}\text { Potential clinical } \\
\text { use }\end{array}$} & \multicolumn{4}{|l|}{ Example study } \\
\hline & & & Study & Studied biomarkers & Subsite & Patients (n) \\
\hline FOXO1/PAX3 & Increased & Poor prognosis & Han, G. H., et al. (2019)114 & FOXO1 / PAX3 & EOC & 212 \\
\hline pStat3 & Increased & Poor prognosis & Li, H., et al. (2020) ${ }^{115}$ & pStat3 & EOC & 156 \\
\hline ATAD2 & Increased & Poor prognosis & Liu, Q., et al. (2020)116 & ATAD2 & OC & 60 \\
\hline \multicolumn{7}{|l|}{ Cell migration } \\
\hline GRO- $\beta$ & Increased & Poor prognosis & Ye, Q., et al. (2015) ${ }^{117}$ & GRO- $\beta$ & OC & 136 \\
\hline B7-H6 & Increased & Poor prognosis & Zhou, Y., et al. (2015)118 & B7-H6 & OC & 110 \\
\hline OCT4, Notch1 and DLL4 & Increased & Poor prognosis & Yu, L., et al. (2016) & $\begin{array}{l}\text { OCT4, Notch1 and } \\
\text { DLL4 }\end{array}$ & $\mathrm{EOC}$ & 207 \\
\hline EphA8 & Increased & Poor prognosis & Liu, X., et al. (2016)120 & EphA8 & OC & 233 \\
\hline AGTR1 & Increased & Poor prognosis & Zhang, Q., et al. (2019)121 & AGTR1 & EOC & 902 \\
\hline \multicolumn{7}{|l|}{ Cell invasion } \\
\hline CK2a & Increased & Poor prognosis & Ma, Z., et al. (2017) ${ }^{122}$ & CK2a & EOC & 117 \\
\hline CEP55 & Increased & Poor prognosis & Zhang, W., et al (2017) & CEP55 & EOC & 213 \\
\hline ANXA1 & Increased & Good prognosis & Manai, M., et al. (2020)124 & ANXA1 & EOC & 156 \\
\hline \multicolumn{7}{|c|}{ Cell proliferation and migration } \\
\hline MAP3К8 & Increased & Poor prognosis & Gruosso, T., et al. (2015)125 & MAP3K8 & HGSOC & 139 \\
\hline IL-33/ST2 axis & Increased & Poor prognosis & Tong, X., et al. (2016) ${ }^{126}$ & IL-33/ST2 axis & EOC & 152 \\
\hline CDCP1, ADAM12 & Decreased & Good prognosis & Vlad, C., et al. $(2016)^{127}$ & CDCP1, ADAM12 & SOC & 102 \\
\hline FGFRL1 & Increased & Poor prognosis & Tai, H., et al. (2018)128 & FGFRL1 & OC & 90 \\
\hline HSDL2 & Increased & Poor prognosis & Sun, Q., et al. (2018) $)^{129}$ & HSDL2 & OC & 74 \\
\hline DUSP2 & Decreased & Poor prognosis & Liu, W., et al. (2019)130 & DUSP2 & HGSOC & 127 \\
\hline Kallistatin (KAL) & Decreased & Poor prognosis & Wu, H., et al. (2019) ${ }^{131}$ & Kallistatin (KAL) & HGSOC & 312 \\
\hline YTHDF1-EIF3C axis & Increased & Poor prognosis & Liu, T., et al. $(2020)^{132}$ & YTHDF1-EIF3C axis & $\mathrm{OC}$ & 134 \\
\hline \multicolumn{7}{|c|}{ Cell proliferation and invasion } \\
\hline IL-6R & Increased & Good prognosis & Isobe, A., et al. (2015) ${ }^{133}$ & IL-6R & OC & 94 \\
\hline Usp7, MARCH7 & Increased & Poor prognosis & Zhang, L., et al. $(2016)^{134}$ & Usp7, MARCH7 & EOC & 121 \\
\hline PPA1 & Increased & Poor prognosis & Li, H., et al. (2017) ${ }^{135}$ & PPA1 & SOC & 139 \\
\hline PATZ1 & Increased & Good prognosis & Zhao, C., et al. (2018) & PATZ1 & SOC & 208 \\
\hline \multicolumn{7}{|c|}{ Cell migration and invasion } \\
\hline ARMC8 & Increased & Poor prognosis & Jiang, G., et al.(2015)137 & ARMC8 & OC & 247 \\
\hline galectin-1 & Increased & Poor prognosis & Chen, L., et al. (2015) & galectin-1 & EOC & 110 \\
\hline MAGE-A9 & Increased & Poor prognosis & Xu, Y., et al. (2015) & MAGE-A9 & EOC & 128 \\
\hline TROP2 & Increased & Poor prognosis & Xu, N., et al. (2016) 140 & TROP2 & EOC & 128 \\
\hline GALNT6 & Increased & Poor prognosis & Lin, T. C., et al. (2017)141 & GALNT6 & EOC & 78 \\
\hline Galectin-1 & Increased & Poor prognosis & Schulz, H., et al. (2017) & Galectin-1 & OC & 156 \\
\hline Galectin-3 & Increased & Poor prognosis & Schulz, H., et al. (2017) & Galectin-3 & OC & 156 \\
\hline Galectin-7 & Increased & Good prognosis & Schulz, H., et al. (2017) & Galectin-7 & OC & 156 \\
\hline REDD1 & Increased & Poor prognosis & Chang, B., et al. (2018) & REDD1 & OC & 229 \\
\hline RacGAP1 & Decreased & Good prognosis & Wang, C., et al. (2018) & RacGAP1 & EOC & 117 \\
\hline PAI-1, PAI-RBP1 & Increased & Poor prognosis & Koensgen, D., et al. (2018) ${ }^{145}$ & PAI-1, PAI-RBP1 & OC & 156 \\
\hline PRDX-1 & Increased & Poor prognosis & Sienko, J., et al. (2019)146 & PRDX-1 & OC & 55 \\
\hline KAI1 & Decreased & Poor prognosis & Yu, L., et al. (2019) ${ }^{98}$ & KAI1 & SOC & 124 \\
\hline CAV1, ATG4C & Increased & Poor prognosis & Zeng, Y., et al. $(2020)^{147}$ & CAV1, ATG4C & EOC & 95 \\
\hline \multicolumn{7}{|c|}{ Cell proliferation, migration and invasion } \\
\hline CH13L1, FKBP4 & Increased & Poor prognosis & Lawrenson, K., et al. (2015) ${ }^{148}$ & CH13L1, FKBP4 & EOC & 200 \\
\hline REG4 & Increased & Poor prognosis & Chen, S., et al. (2015)149 & REG4 & EOC & 337 \\
\hline Spry2 & Decreased & Poor prognosis & Masoumi-Moghaddam, S., et al. (2015)150 & Spry2 & OC & 99 \\
\hline SWI/SNF subunits & Decreased & Poor prognosis & Abou-Taleb, H., et al. (2016) ${ }^{151}$ & SWI/SNF subunits & EOC & 152 \\
\hline KIF2A & Decreased & Poor prognosis & Wang, D., et al. (2016) ${ }^{152}$ & KIF2A & EOC & 111 \\
\hline Salusin- $\beta$ & Increased & Poor prognosis & Zhang,Q.,et al.(2017) ${ }^{153}$ & Salusin- $\beta$ & OC & 57 \\
\hline P38a, ATF2 & Increased & Poor prognosis & Song,W.J.,et al.(2017) & P38a, ATF2 & OSC & 120 \\
\hline $\mathrm{nER} \beta 5$ & Increased & Poor prognosis & Chan, K. K. L., et al. (2017) & $\mathrm{nER} \beta 5$ & OC & 106 \\
\hline SENP3/SMT3IP1 & Increased & Poor prognosis & Cheng, J., et al. (2017)156 & SENP3/SMT3IP1 & EOC & 124 \\
\hline BCL6, Lewis y & Increased & Poor prognosis & Zhu, L., et al. (2017)157 & BCL6, Lewis y & OC & 103 \\
\hline CXCL11, HMGA2 & Increased & Poor prognosis & Jin, C., et al. (2018) & CXCL11, HMGA2 & HGSOC & 110 \\
\hline HS3ST2 & Decreased & Poor prognosis & Huang, R.L., et al. (2018)159 & HS3ST2 & EOC & 115 \\
\hline KIF2A & Increased & Poor prognosis & Sheng, N., et al. (2018) & KIF2A & OC & 108 \\
\hline TRIM59 & Increased & Good prognosis & Wang, Y., et al. (2018) ${ }^{161}$ & TRIM59 & OC & 192 \\
\hline S100A10 & Increased & Poor prognosis & Wang, L., et al. (2019) 162 & S100A10 & OC & 138 \\
\hline PYGB & Increased & Poor prognosis & Zhou, Y., et al. (2019) & PYGB & OC & 94 \\
\hline \multicolumn{7}{|c|}{ Glycosylation disorder of protein } \\
\hline GalNAs T6, T14 & Increased & Poor prognosis & Sheta, R., et al. (2017) ${ }^{164}$ & GalNAs T6, T14 & HGSOC & 131 \\
\hline \multicolumn{7}{|l|}{ Mitotic process } \\
\hline TOPK & Increased & Poor prognosis & Ikeda, Y., et al. (2016) ${ }^{165}$ & TOPK & EOC & 163 \\
\hline HER2, AURKA & Increased & Poor prognosis & Li, M.J., et al. (2017)166 & HER2, AURKA & OCCC & 60 \\
\hline KIF14 & Increased & Poor prognosis & Qiu, H. L., et al. (2017) ${ }^{167}$ & KIF14 & $\mathrm{EOC}$ & 170 \\
\hline Apoptosis process & & & & & & \\
\hline PDCD5 & Decreased & Poor prognosis & Gao, L., et al. (2015) ${ }^{168}$ & PDCD5 & OC & 127 \\
\hline
\end{tabular}




\begin{tabular}{|c|c|c|c|c|c|c|}
\hline & \multirow{2}{*}{$\begin{array}{l}\text { Expression or } \\
\text { ratio }\end{array}$} & \multirow{2}{*}{$\begin{array}{l}\text { Potential clinical } \\
\text { use }\end{array}$} & \multicolumn{4}{|l|}{ Example study } \\
\hline & & & Study & Studied biomarkers & Subsite & Patients (n) \\
\hline MDM2 & Increased & Poor prognosis & Makii, C., et al. (2016) 169 & MDM2 & OCCC & 75 \\
\hline DNA-PKcs, Akt3, p53 & Increased & Poor prognosis & Shin, K., et al. (2016) ${ }^{170}$ & DNA-PKcs, Akt3, p53 & SOC & 132 \\
\hline Gal-1, Gal-8, Gal-9p & Increased & Poor prognosis & Labrie, M., et al. (2017) $)^{171}$ & Gal-1, Gal-8, Gal-9p & HGSOC & 209 \\
\hline \multicolumn{7}{|c|}{ Cell survival (telomerase activity) } \\
\hline Phosphorylated Akt, hTERT & Increased & Poor prognosis & Lee, Y. K., et al. (2015) ${ }^{172}$ & $\begin{array}{l}\text { phosphorylated Akt, } \\
\text { hTERT }\end{array}$ & EOC & 92 \\
\hline JARID1B & Increased & Poor prognosis & Wang, L., et al. (2015) ${ }^{173}$ & JARID1B & EOC & 120 \\
\hline ALDH1 & Increased & Good prognosis & Ayub, T. H., et al. (2015) $)^{174}$ & ALDH1 & EOC & 55 \\
\hline PRP4K & Increased & Good prognosis & Corkery, D. P., et al. (2015) ${ }^{175}$ & PRP4K & OC & 199 \\
\hline HtrA2 & Decreased & Poor prognosis & Miyamoto, M., et al. (2015)176 & HtrA2 & HGSOC & 142 \\
\hline PTEN & Increased & Good prognosis & Wang, L., et al. (2015)177 & PTEN & EOC & 161 \\
\hline NF-кBp65 & Increased & Poor prognosis & Wang, L., et al. (2015)177 & NF-кBp65 & EOC & 161 \\
\hline eIF3a & Increased & Good prognosis & Zhang, Y., et al. (2015) ${ }^{178}$ & eIF3a & OC & 126 \\
\hline GTF2H5 & Decreased & Good prognosis & Gayarre, J., et al. (2016)179 & GTF2H5 & HGSOC & 117 \\
\hline SOX10 & Increased & Poor prognosis & Know, A.Y., et al. (2016) $)^{181}$ & SOX10 & EOC & 203 \\
\hline GOLPH3L & Increased & Poor prognosis & He, S., et al. (2017) ${ }^{182}$ & GOLPH3L & OC & 177 \\
\hline LC3A & Increased & Poor prognosis & Miyamoto, M., et al. (2017)183 & LC3A & OCCC & 117 \\
\hline Stonin 2 (STON2) & Increased & Poor prognosis & Sun, X., et al. (2017) ${ }^{184}$ & Stonin 2 (STON2) & EOC & 89 \\
\hline GATA3 & Increased & Poor prognosis & Chen, H. J., et al. (2018) $)^{185}$ & GATA3 & OC & 196 \\
\hline EpCAM & Increased & Poor prognosis & Zhang, X., et al. (2018) & EpCAM & EOC & 109 \\
\hline UBC13 & Decreased & Poor prognosis & Zhang, X., et al. (2018) ${ }^{187}$ & UBC13 & OC & 71 \\
\hline $14-3-3 \zeta$ & Increased & Poor prognosis & Kim, H. J., et al. (2018) ${ }^{188}$ & $14-3-3 \zeta$ & OC & 88 \\
\hline KCNN3 & Increased & Poor prognosis & Liu, X., et al. (2018) $)^{189}$ & KCNN3 & OC & 57 \\
\hline HELQ & Increased & Poor prognosis & Long, J., et al. (2018) $)^{190}$ & HELQ & EOC & 87 \\
\hline P15 PAF (KIAA0101) & Increased & Poor prognosis & Jin, C., et al. (2018) ${ }^{191}$ & P15 PAF (KIAA0101) & HGSOC & 118 \\
\hline UTP23 & Decreased & Poor prognosis & Fu, Z., et al. (2019)192 & UTP23 & OC & 133 \\
\hline ABCB9 & Decreased & Poor prognosis & Hou, L., et al. (2019) ${ }^{193}$ & АВСB9 & OC & 308 \\
\hline PBK & Increased & Poor prognosis & Ma, H., et al. (2019)194 & PBK & HGSOC & 234 \\
\hline Sorcin & Decreased & Good prognosis & Zhang, S., et al. (2019)195 & Sorcin & OC & 60 \\
\hline \multicolumn{7}{|l|}{ Cell cycle regulation } \\
\hline CAP1 & Increased & Poor prognosis & Hua, M., et al. (2015) ${ }^{198}$ & CAP1 & EOC & 119 \\
\hline CCNE1 & Increased & Poor prognosis & Ayhan, A., et al. (2017)199 & CCNE1 & OCCC & 120 \\
\hline NUCKS & Increased & Poor prognosis & Shi, C., et al. (2017) 200 & NUCKS & OC & 121 \\
\hline TK1 & Increased & Poor prognosis & Wang, J., et al. (2017) 201 & TK1 & SOC & 109 \\
\hline \multicolumn{7}{|c|}{ Differentiation of cancer-associated fibroblasts (CAFs) } \\
\hline MARCKS & Increased & Poor prognosis & Doghri, R., et al. (2017) $)^{202}$ & MARCKS & EOC & 118 \\
\hline \multicolumn{7}{|l|}{ Immunosuppression } \\
\hline VEGF & Increased & Poor prognosis & Horikawa, N., et al. (2017) 203 & VEGF & HGSOC & 56 \\
\hline \multicolumn{7}{|l|}{ Metabolic reprogramming } \\
\hline TBC1D8 & Increased & Poor prognosis & Chen, M., et al. (2019) 204 & TBC1D8 & OC & 141 \\
\hline \multicolumn{7}{|l|}{ Fatty acid metabolism } \\
\hline PAX2 & Increased & Poor prognosis & Feng, Y., et al. (2020) 205 & PAX2 & EOC & 152 \\
\hline \multicolumn{7}{|l|}{ Defective DNA repair } \\
\hline WRAP53 $\beta$ & Decreased & Poor prognosis & Hedström, E., et al. (2015)206 & WRAP53 $\beta$ & EOC & 151 \\
\hline $\mathrm{pH} 2 \mathrm{AX}$ & Increased & Poor prognosis & Mei, L., et al. (2015)207 & $\mathrm{pH} 2 \mathrm{AX}$ & EOC & 87 \\
\hline \multicolumn{7}{|l|}{ Others } \\
\hline SLP-2 & Increased & Poor prognosis & Sun, F., et al. (2015) ${ }^{208}$ & SLP-2 & EOC & 140 \\
\hline CD44v8-10 & Expression & Good prognosis & Sosulski, A., et al. (2016) ${ }^{209}$ & CD44v8-10 & SOC & 210 \\
\hline P53 & Increased & Poor prognosis & Zuo, J., et al. (2016) 210 & P53 & SOC & 183 \\
\hline Highly sulfated CS & Increased & Poor prognosis & Van der steen, S.C., et al. (2016) $)^{211}$ & Highly sulfated CS & EOC & 255 \\
\hline $\begin{array}{l}\text { Adiponectin receptor-1 } \\
\text { (AdipoR1) }\end{array}$ & Increased & Good prognosis & Li, X., et al. (2017)212 & $\begin{array}{l}\text { Adiponectin receptor-1 } \\
\text { (AdipoR1) }\end{array}$ & EOC & 73 \\
\hline TP53 & Increased & Poor prognosis & Rzepecka, I. K., et al. (2017)213 & TP53 & HGSOC & 159 \\
\hline SMAD3 & Increased & Poor prognosis & Sakr, S., et al. $(2017)^{214}$ & SMAD3 & GCT & 88 \\
\hline ALDH5A1 & Increased & Good prognosis & Tian, X., et al. (2017) $)^{215}$ & ALDH5A1 & OC & 192 \\
\hline GR & Increased & Poor prognosis & Veneris, J. T., et al. (2017)216 & GR & EOC & 341 \\
\hline LAMP3 & Increased & Poor prognosis & Wang, D., et al. (2017) $)^{217}$ & LAMP3 & EOC & 135 \\
\hline HBXIP & Increased & Poor prognosis & Wang, Y., et al. (2017)218 & HBXIP & OC & 120 \\
\hline HSF1 pSer326 & Expression & Poor prognosis & Yasuda, K., et al. (2017) 219 & HSF1 pSer326 & EOC & 122 \\
\hline COX-1, COX-2 & Increased & Poor prognosis & Beeghly-Fadiel, A., et al. (2018) 220 & COX-1, COX-2 & EOC & 190 \\
\hline GPR30 & Expression & Poor prognosis & Zhu, C. X., et al. (2018) 221 & GPR30 & EOC & 110 \\
\hline
\end{tabular}




\begin{tabular}{|c|c|c|c|c|c|c|}
\hline & \multirow{2}{*}{$\begin{array}{l}\text { Expression or } \\
\text { ratio }\end{array}$} & \multirow{2}{*}{$\begin{array}{l}\text { Potential clinical } \\
\text { use }\end{array}$} & \multicolumn{4}{|l|}{ Example study } \\
\hline & & & Study & Studied biomarkers & Subsite & Patients (n) \\
\hline ANXA8 & Increased & Poor prognosis & Gou, R., et al. (2019) ${ }^{225}$ & ANXA8 & $\mathrm{OC}$ & 122 \\
\hline USP10/p14ARF & Decreased & Poor prognosis & Han, G. H., et al. (2019)226 & USP10/p14ARF & EOC & 212 \\
\hline PKP3 & Increased & Poor prognosis & Qian, H., et al. (2019) 227 & PKP3 & OC & 157 \\
\hline PDGFR- $\beta$ & Expression & Good prognosis & Szubert, S., et al. (2019) 228 & PDGFR- $\beta$ & $\mathrm{EOC}$ & 52 \\
\hline $\mathrm{CN}$ & Increased & Poor prognosis & Xin, B., et al. (2019)229 & $\mathrm{CN}$ & OC & 50 \\
\hline TSLP & Increased & Poor prognosis & Xu, L., et al. (2019) 230 & TSLP & EOC & 144 \\
\hline BUB1B, KIF11 and KIF20A & Increased & Poor prognosis & Zhang, L., et al. (2019)231 & $\begin{array}{l}\text { BUB1B, KIF11 and } \\
\text { KIF20A }\end{array}$ & OC & 50 \\
\hline VDR & Increased & Poor prognosis & Czogalla, B., et al. (2020)232 & VDR & EOC & 156 \\
\hline
\end{tabular}

Abbreviations: TIL: tumor infiltrates lymphocytes; Gal: Galectin; OC: ovarian cancer; HGSOC: High grade serous ovarian cancer; EOC: epithelial ovarian cancer.

Table 3. Tissue-based DNA biomarkers in ovarian cancer

\begin{tabular}{|c|c|c|c|c|c|c|c|}
\hline & \multirow{2}{*}{$\begin{array}{l}\text { Expression or } \\
\text { ratio }\end{array}$} & \multirow{2}{*}{$\begin{array}{l}\text { Potential clinical } \\
\text { use }\end{array}$} & \multicolumn{5}{|l|}{ Example study } \\
\hline & & & Study & Studied biomarkers & Method & Subsite & Patients (n) \\
\hline \multicolumn{8}{|l|}{ Methylation } \\
\hline MYLK3 Methylation & Increased & Good prognosis & Phelps, D.L., et al. (2017) ${ }^{233}$ & MYLK3 Methylation & Pyrosequencing & SOC & 803 \\
\hline HNF1B & Expression & Poor prognosis & Bubancova, I., et al. (2017) 234 & HNF1B & $\begin{array}{l}\text { NGS, HRM, } \\
\text { MS-PCR }\end{array}$ & OC & 64 \\
\hline GATA4 & Expression & Good prognosis & Bubancova, I., et al. (2017) 234 & GATA4 & $\begin{array}{l}\text { NGS, HRM, } \\
\text { MS-PCR }\end{array}$ & OC & 64 \\
\hline HS3ST2 & Increased & Poor prognosis & Huang, R.L., et al. (2018) ${ }^{159}$ & HS3ST2 & TMA & EOC & 115 \\
\hline ZNF671 & Increased & Early relapse & Mase, S., et al. (2019) 235 & ZNF671 & Pyrosequencing & HGSOC & 78 \\
\hline \multicolumn{8}{|c|}{ Structural changes of nuclear chromatin } \\
\hline Chromatin entropy nuclei & Increased & Poor prognosis & Nielsen, B. et al. (2018) 236 & $\begin{array}{l}\text { Chromatin entropy } \\
\text { nuclei }\end{array}$ & $\begin{array}{l}\text { Nuclear Texture } \\
\text { analysis }\end{array}$ & OC & 246 \\
\hline \multicolumn{8}{|l|}{ Mutation status } \\
\hline BRCA1/2 wild type & Expression & Poor prognosis & Eoh, K. J., et al. (2017) $)^{237}$ & BRCA1/2 wild type & Direct sequencing & EOC & 116 \\
\hline BRCA1/2 & Expression & Good prognosis & Kim, S. I., et al. (2019) 238 & BRCA1/2 & Sanger sequencing & HGSOC & 128 \\
\hline \multicolumn{8}{|c|}{ Cell proliferation and apoptosis } \\
\hline ecDNA & Increased & Poor prognosis & Kalavska, K., et al. (2018) 239 & ecDNA & RT-PCR & $\mathrm{OC}$ & 67 \\
\hline \multicolumn{8}{|l|}{ Gene polymorphism } \\
\hline $\begin{array}{l}\text { The AT genotype of } \\
\text { rs189897 }\end{array}$ & Expression & Poor prognosis & Liu, J., et al. (2019) $)^{240}$ & $\begin{array}{l}\text { The AT genotype of } \\
\text { rs189897 }\end{array}$ & Mass ARRAY & EOC & 200 \\
\hline rs12921862 C/C & Expression & Good prognosis & Zhang, Y., et al. (2019)241 & rs12921862 C/C & PCR-RFLP & EOC & 165 \\
\hline
\end{tabular}

Abbreviations: TMA: tissue microarrays; NGS: Next Generation Sequencing; MS-PCR: Methylation-Specific PCR; RT-PCR: real time polymerase chain reaction; PCR-RFLP: polymerase chain reaction-restriction fragment length polymorphism.

Table 4. Tissue-based RNA biomarkers in ovarian cancer

\begin{tabular}{|c|c|c|c|c|c|c|c|}
\hline & \multirow{2}{*}{$\begin{array}{l}\text { Expression or } \\
\text { ratio }\end{array}$} & \multirow{2}{*}{$\begin{array}{l}\text { Potential clinical } \\
\text { use }\end{array}$} & \multicolumn{5}{|l|}{ Example study } \\
\hline & & & Study & Studied biomarkers & Method & Subsite & Patients (n) \\
\hline \multicolumn{8}{|l|}{ Cell proliferation } \\
\hline microRNA(miR)-498 & Decreased & Poor prognosis & Cong, J., et al. (2015) & microRNA(miR)-498 & qRT-PCR & OC & 175 \\
\hline miR-193b & Decreased & Poor prognosis & Li, H., et al. (2015) 243 & miR-193b & qRT-PCR & OC & 116 \\
\hline miR-572 & Decreased & Good prognosis & Zhang, X., et al. (2015) ${ }^{244}$ & miR-572 & qRT-PCR & OC & 108 \\
\hline $\mathrm{C} 7$ & Decreased & Poor prognosis & Ying, L., et al. (2016) & $\mathrm{C} 7$ & qRT-PCR & OC & 156 \\
\hline HER2, STAT3 & Increased & Poor prognosis & Shang, A. Q., et al. (2017) ${ }^{246}$ & HER2, STAT3 & qRT-PCR & OC & 136 \\
\hline SOCS3 & Decreased & Poor prognosis & Shang, A. Q., et al. (2017) & SOCS3 & qRT-PCR & OC & 136 \\
\hline lncRNA RAD51-AS1 & Increased & Poor prognosis & Zhang, X., et al. (2017)247 & lncRNA RAD51-AS1 & qRT-PCR & EOC & 163 \\
\hline lncRNA LINC 00152 & Increased & Poor prognosis & Chen, P., et al. $(2018)^{248}$ & lncRNA LINC 00152 & qRT-PCR & $\mathrm{OC}$ & 82 \\
\hline miR-1294 & Increased & Good prognosis & Guo, T. Y., et al. (2018)249 & miR-1294 & qRT-PCR & EOC & 76 \\
\hline lncRNA TUG1 & Increased & Poor prognosis & Li, T. H., et al. (2018) & lncRNA TUG1 & qRT-PCR & EOC & 96 \\
\hline $\begin{array}{l}\text { microRNA-424-5p } \\
\text { (miR-424-5p) }\end{array}$ & Increased & Good prognosis & Liu, J., et al. (2018) 251 & $\begin{array}{l}\text { microRNA-424-5p } \\
\text { (miR-424-5p) }\end{array}$ & qRT-PCR & EOC & 83 \\
\hline \multicolumn{8}{|l|}{ Cell migration } \\
\hline lncRNA LINC00092 & Increased & Poor prognosis & Zhao, L., et al. (2017) ${ }^{252}$ & lncRNA LINC00092 & qRT-PCR & SOC & 58 \\
\hline lncRNA PTPRG-AS1 & Increased & Poor prognosis & Ren, X. Y., et al. (2020)253 & lncRNA PTPRG-AS1 & qRT-PCR & EOC & 184 \\
\hline \multicolumn{8}{|l|}{ Cell invasion } \\
\hline lncRNA NEAT1 & Increased & Poor prognosis & Chen, Z. J., et al. (2016) ${ }^{254}$ & lncRNA NEAT1 & qRT-PCR & $\mathrm{OC}$ & 149 \\
\hline ASAP1-IT1 & Increased & Good prognosis & Fu, Y., et al. (2016) 255 & ASAP1-IT1 & qRT-PCR & EOC & 266 \\
\hline \multicolumn{8}{|c|}{ Cell proliferation and migration } \\
\hline miR-145 & Decreased & Poor prognosis & Kim,T.H.,et al.(2015)256 & miR-145 & qRT-PCR & HGSOC & 74 \\
\hline microRNA-196a & Increased & Poor prognosis & Fan, Y., et al. (2015) $)^{257}$ & microRNA-196a & qRT-PCR & EOC & 156 \\
\hline $\operatorname{miR}-552$ & Increased & Poor prognosis & Zhao, W., et al. (2019) 258 & $\operatorname{miR}-552$ & qRT-PCR & $\mathrm{OC}$ & 110 \\
\hline \multicolumn{8}{|c|}{ Cell proliferation and invasion } \\
\hline IncRNA AB073614 & Increased & Poor prognosis & Cheng, Z., et al. (2015) 259 & lncRNA AB073614 & qRT-PCR & OC & 75 \\
\hline
\end{tabular}




\begin{tabular}{|c|c|c|c|c|c|c|c|}
\hline & \multirow{2}{*}{$\begin{array}{l}\text { Expression or } \\
\text { ratio }\end{array}$} & \multirow{2}{*}{$\begin{array}{l}\text { Potential clinical } \\
\text { use }\end{array}$} & \multicolumn{5}{|l|}{ Example study } \\
\hline & & & Study & Studied biomarkers & Method & Subsite & Patients (n) \\
\hline TBL1XR1 & Increased & Poor prognosis & Ma, M. and N. Yu (2017) $)^{260}$ & TBL1XR1 & qRT-PCR & SOC & 116 \\
\hline lncRNA MNX1-AS1 & Increased & Poor prognosis & $\begin{array}{l}\text { Li, A. H. and H. H. Zhang } \\
(2017)^{261}\end{array}$ & lncRNA MNX1-AS1 & qRT-PCR & EOC & 177 \\
\hline lncRNA NEAT1 & Increased & Poor prognosis & Yong, W., et al. (2018)262 & lncRNA NEAT1 & qRT-PCR & HGSOC & 75 \\
\hline miR-532-5p & Decreased & Poor prognosis & Wei, H., et al. (2018) 263 & miR-532-5p & qRT-PCR & EOC & 145 \\
\hline \multicolumn{8}{|c|}{ Cell migration and invasion } \\
\hline ANRIL & Increased & Poor prognosis & Qiu,J.J.,et al.(2015)264 & ANRIL & qRT-PCR & SOC & 68 \\
\hline lncRNA CCAT1 & Increased & Poor prognosis & Cao,Y.,et al.(2017) ${ }^{265}$ & lncRNA CCAT1 & qRT-PCR & EOC & 72 \\
\hline miR-208a-5p & Increased & Good prognosis & Mei, J., et al. (2019)266 & miR-208a-5p & qRT-PCR & OC & 61 \\
\hline STAT2 & Increased & Poor prognosis & Chen, X., et al. $(2020)^{267}$ & STAT2 & RT-PCR & OC & 62 \\
\hline lncRNA miR503HG & Decreased & Poor prognosis & Zhu, D., et al. (2020) 268 & lncRNA miR503HG & qRT-PCR & $\mathrm{OC}$ & 61 \\
\hline \multicolumn{8}{|c|}{ Cell proliferation, migration and invasion } \\
\hline lncRNA CCAT2 & Increased & Poor prognosis & Huang,S.,et al.(2016) 269 & lncRNA CCAT2 & qRT-PCR & OC & 109 \\
\hline GOLPH3 & Increased & Poor prognosis & Sun, J., et al. (2017) 270 & GOLPH3 & qRT-PCR & EOC & 73 \\
\hline lncRNA HOXA11as & Increased & Poor prognosis & Yim, G. W., et al. (2017)271 & lncRNA HOXA11as & qRT-PCR & SOC & 129 \\
\hline miR-520h & Increased & Poor prognosis & Zhang, J., et al. (2018) ${ }^{272}$ & miR-520h & qRT-PCR & EOC & 116 \\
\hline lncRNA SNHG16 & Increased & Poor prognosis & Yang, X. S., et al. (2018) & lncRNA SNHG16 & qRT-PCR & OC & 103 \\
\hline lncRNA EBIC & Increased & Poor prognosis & Xu, Q. F., et al. (2018) $)^{274}$ & lncRNA EBIC & qRT-PCR & OC & 126 \\
\hline lncRNA MALAT1 & Increased & Poor prognosis & Guo, C., et al. $(2018)^{275}$ & lncRNA MALAT1 & qRT-PCR & OC & 60 \\
\hline $\begin{array}{l}\text { lncRNA RP11- } \\
\text { 552M11.4 }\end{array}$ & Increased & Poor prognosis & Huang, K., et al. (2018) ${ }^{276}$ & IncRNA RP11-552M11.4 & qRT-PCR & EOC & 67 \\
\hline $\begin{array}{l}\text { IncRNA OTUB1- } \\
\text { isoform2 }\end{array}$ & Increased & Poor prognosis & Wang, S., et al. (2018)277 & lncRNA OTUB1-isoform2 & qRT-PCR & OC & 114 \\
\hline HYOU1 & Increased & Poor prognosis & Li, X., et al. (2019) 278 & HYOU1 & qRT-PCR & EOC & 127 \\
\hline miR-203a-3p & Increased & Good prognosis & Liu, H. Y., et al. (2019)279 & $\operatorname{miR}-203 a-3 p$ & qRT-PCR & OC & 152 \\
\hline LINC00339 & Increased & Poor prognosis & Pan, L., et al. (2019) 280 & LINC00339 & qRT-PCR & OC & 75 \\
\hline lncRNA SNHG20 & Increased & Poor prognosis & Wang, D., et al. (2019) 281 & lncRNA SNHG20 & RT-PCR & EOC & 60 \\
\hline miR-149 & Increased & Good prognosis & Zhao, L. W., et al. (2020) ${ }^{282}$ & $\operatorname{miR}-149$ & qRT-PCR & OC & 72 \\
\hline \multicolumn{8}{|c|}{ Chemotherapeutic sensitivity } \\
\hline $\begin{array}{l}\text { microRNA-506 } \\
(\mathrm{miR}-506)\end{array}$ & Increased & Good prognosis & Liu, G., et al. (2015) ${ }^{283}$ & microRNA-506 (miR-506) & qRT-PCR & EOC & 598 \\
\hline CHI3L1 & Increased & Poor prognosis & Chiang, Y. C., et al. (2015) ${ }^{284}$ & CHI3L1 & qRT-PCR & EOC & 180 \\
\hline IMP3 & Increased & Poor prognosis & Hsu, K. F., et al. (2015) 285 & IMP3 & qRT-PCR & EOC & 140 \\
\hline $\operatorname{Lin} 28 B$ & Increased & Poor prognosis & Hsu, K. F., et al. (2015) 285 & Lin28B & qRT-PCR & EOC & 140 \\
\hline Tribbles 2 (TRIB2) & Decreased & Poor prognosis & Kritsch, D., et al. (2017) ${ }^{286}$ & Tribbles 2 (TRIB2) & qRT-PCR & EOC & 149 \\
\hline let-7e & Decreased & Poor prognosis & Xiao, M., et al. (2017) 287 & let-7e & qRT-PCR & EOC & 84 \\
\hline MAL & Increased & Poor prognosis & Zanotti, L., et al. (2017) 288 & MAL & qRT-PCR & HGSOC & 74 \\
\hline miR-98-5p & Increased & Good prognosis & Wang, Y., et al. (2018) 289 & miR-98-5p & qRT-PCR & EOC & 97 \\
\hline $\operatorname{miR}-1180$ & Increased & Poor prognosis & Gu, Z. W., et al. (2019) 290 & miR-1180 & qRT-PCR & OC & 59 \\
\hline lncRNA GAS5 & Increased & Good prognosis & Long, X., et al. (2019) $)^{291}$ & lncRNA GAS5 & qRT-PCR & EOC & 53 \\
\hline \multicolumn{8}{|l|}{ Immune response } \\
\hline APOBEC3G & Increased & Good prognosis & Leonard, B., et al. (2016) ${ }^{292}$ & APOBEC3G & qRT-PCR & HGSOC & 354 \\
\hline IncRNA MIR155HG & Increased & Good prognosis & Colvin, E. K., et al. (2020) $)^{293}$ & lncRNA MIR155HG & qRT-PCR & HGSOC & 67 \\
\hline \multicolumn{8}{|c|}{ Chromosome structure and function } \\
\hline $\begin{array}{l}\text { SMYD3 genetic } \\
\text { polymorphisms }\end{array}$ & Expression & Poor prognosis & Liu, T. T., et al. (2016) 294 & $\begin{array}{l}\text { SMYD3 genetic } \\
\text { polymorphisms }\end{array}$ & qRT-PCR & OC & 154 \\
\hline \multicolumn{8}{|l|}{ Apoptosis process } \\
\hline CPS1-IT1 & Increased & Good prognosis & Wang, Y. S., et al. (2017) ${ }^{295}$ & CPS1-IT1 & qRT-PCR & EOC & 91 \\
\hline \multicolumn{8}{|l|}{ Others } \\
\hline CRNDE & Increased & Poor prognosis & Szafron, L. M., et al. (2015)296 & CRNDE & qRT-PCR & OC & 135 \\
\hline $\begin{array}{l}\text { GADD45A } \\
(1506 \mathrm{~T}>\mathrm{C})\end{array}$ & Increased & Poor prognosis & Yuan, C., et al. (2015) 297 & GADD45A (1506T> C) & qRT-PCR & OC & 258 \\
\hline miR-510, miR-129-3P & Decreased & Poor prognosis & Zhang,X.,et al.(2015) $)^{298}$ & miR-510, miR-129-3P & RT-qPCR,ISH & EOC & 78 \\
\hline FAM215A & Increased & Good prognosis & Fu, Y., et al. $(2016)^{255}$ & FAM215A & qRT-PCR & EOC & 266 \\
\hline $\begin{array}{l}\text { LIN-28B/let-7a/ } \\
\text { IGF-II axis }\end{array}$ & $\begin{array}{l}\text { LIN-28Blowlet- } \\
\text { 7alow or } \\
\text { LIN-28Blowlet- } \\
\text { 7ahighIGF-IIlow }\end{array}$ & Good prognosis & Lu, L., et al. (2016)299 & $\begin{array}{l}\text { LIN-28B/let-7a/IGF-II } \\
\text { axis }\end{array}$ & qRT-PCR & EOC & 211 \\
\hline $\begin{array}{l}\text { miR-200b, miR-1274A } \\
\text { (tRNA Lys5) and } \\
\text { miR-141 }\end{array}$ & Decreased & Good prognosis & Halvorsen, A. R., et al. (2017) 300 & $\begin{array}{l}\text { miR-200b, miR-1274A } \\
\text { (tRNA Lys5) and miR-141 }\end{array}$ & qRT-PCR & OC & 207 \\
\hline miR-595 & Decreased & Poor prognosis & Zhou, Q. H., et al. (2017) $)^{301}$ & $\operatorname{miR}-595$ & qRT-PCR & EOC & 166 \\
\hline KLK11, KLK15 & Increased & Good prognosis & Geng,X.,et al.(2017) $)^{302}$ & KLK11, KLK15 & RT-PCR & HGSOC & 139 \\
\hline lncRNA LINC01088 & Decreased & Poor prognosis & Ai, H., et al. (2018) 303 & lncRNA LINC01088 & qRT-PCR & EOC & 184 \\
\hline lncRNA HMMR-AS1 & Increased & Poor prognosis & Chu, Z. P., et al. (2018) & lncRNA HMMR-AS1 & qRT-PCR & EOC & 152 \\
\hline circ LARP4 & Decreased & Poor prognosis & Zou, T., et al. (2018) $)^{305}$ & circ LARP4 & qRT-PCR & OC & 78 \\
\hline circ HIPK3 & Increased & Poor prognosis & Liu, N., et al. (2018) $)^{306}$ & circ HIPK3 & qRT-PCR & EOC & 69 \\
\hline lncRNA DGCR5 & Decreased & Poor prognosis & Chen, H., et al. (2019) ${ }^{307}$ & lncRNA DGCR5 & qRT-PCR & OC & 66 \\
\hline
\end{tabular}




\begin{tabular}{|c|c|c|c|c|c|c|c|}
\hline & \multirow{2}{*}{$\begin{array}{l}\text { Expression or } \\
\text { ratio }\end{array}$} & \multirow{2}{*}{$\begin{array}{l}\text { Potential clinical } \\
\text { use }\end{array}$} & \multicolumn{5}{|l|}{ Example study } \\
\hline & & & Study & Studied biomarkers & Method & Subsite & Patients (n) \\
\hline FANCD2 & Increased & Poor prognosis & $\begin{array}{l}\text { Moes-Sosnowska, J., et al. } \\
(2019)^{308}\end{array}$ & FANCD2 & qRT-PCR & OC & 99 \\
\hline AK7 & Decreased & Poor prognosis & Zhang, X. Y., et al. (2021) 309 & AK7 & RNAseq & OC & 308 \\
\hline
\end{tabular}

Abbreviations: lnc: Long non-coding RNA; circ: circular; qRT-PCR: quantitative real time polymerase chain reaction; RT-PCR: real time polymerase chain reaction; IHC: Immunohistochemistry; ISH, in situ hybridization.

\section{Classic prognostic factors}

Clinicopathologic factors and serum CA125 level are independent factors affecting the prognosis of ovarian cancer patients, which have been widely used to guide accurate and reasonable clinical treatment, so as to improve the survival rate of patients.

\section{Clinicopathological factors}

The clinicopathological factors that affect the prognosis of ovarian cancer mainly include: FIGO stage, degree of differentiation, degree of tumor reduction surgery, course of chemotherapy. Previous literature has reported the importance of ovarian cancer staging for prognosis and treatment options, ovarian cancer can be classified as stage I-IV according to FIGO staging criteria, and most patients have stage III disease. Studies have shown that patients with stage I ovarian cancer have a 5-year survival rate of more than $90 \%$; when ovarian cancer is confined to the pelvis (stage II), the estimated 5-year survival rate is about $70 \%$; when ovarian cancer has spread to the entire abdominal cavity (stage III) or to distant parts (stage IV), the 5-year survival rate is less than $30 \%$ [4]. The survival prognosis of patients in the early stage was significantly better than that in the late stage. Differentiation degree of ovarian cancer includes high differentiation, moderate differentiation and low differentiation (poor differentiation), there has been evidence that poor differentiation of ovarian cancer is associated with worse survival. A large sample study established a predictive model for overall survival in 1189 patients with primary ovarian epithelial carcinoma, cox regression analysis showed that the worse the differentiation, the greater the risk of death [5].

Surgery is the most effective treatment for ovarian cancer, once suspected for ovarian cancer, should be performed as early as possible. Staging surgery is performed for early stage cancer, including resection of the tumor and definite staging. Tumor cell reduction was performed for advanced cancer, and the primary tumor and all metastases were removed as far as possible to minimize the number of tumor cells. Studies have confirmed that the degree of tumor cell reduction and the number of residual lesions after the first operation are important prognostic factors for advanced ovarian cancer [6]. The research of Jing shui et al. shows that the size of residual tumor foci was negatively correlated with the survival rate of patients and those with residual tumor foci $\leq 2 \mathrm{~cm}$ had better prognosis [7]. It is helpful to improve the prognosis and long-term survival rate of patients by minimizing or removing residual tumor foci.

Chemotherapy is an important adjuvant treatment for ovarian cancer, and most ovarian cancer is sensitive to chemotherapy. Platinum-based drugs (cisplatin and carboplatin) and taxanes (paclitaxel and docetaxel) are chemotherapy drugs commonly used in the treatment of ovarian cancer [8]. Postoperative adjuvant chemotherapy should follow the principles of standard, early and adequate course of treatment. Currently, it is generally considered that the standard course of chemotherapy for ovarian cancer is 6 courses. Three trials of primary advanced ovarian cancer compared the efficacy of chemotherapy with cisplatin in 5-6 cycles and 8-12 cycles, and the results showed that there was no benefit after 6 cycles of chemotherapy [9]. Another study on prognostic factor analysis of 129 cases of epithelial ovarian cancer showed that the median OS of patients with postoperative chemotherapy course $\geq 6$ courses was significantly higher than that of patients with less than 6 courses of chemotherapy, and the difference was statistically significant $(P<0.0001)$. There was no statistically significant difference in median OS in patients with 6 courses of chemotherapy, 7 courses of chemotherapy, 8 courses of chemotherapy or more than 8 courses of chemotherapy $(P=0.816)$ [10]. In summary, postoperative chemotherapy course is an important prognostic factor for ovarian cancer, and standard chemotherapy course is associated with higher overall survival.

\section{CA125}

CA125, encoded by the MUC16 gene, is a classic marker for the diagnosis of ovarian cancer and was first described in the study of Bast RC et al [11]. Serum CA125 lacks sensitivity and specificity and cannot be used as a single marker for early detection of ovarian cancer $[12,13]$, but the CA125 value after surgery and chemotherapy plays an important role in monitoring recurrence and evaluating prognosis. Redman et al. detected the CA125 value before the third chemotherapy in 78 patients with stage II IV ovarian cancer after the completion of two courses of 
chemotherapy, and the analysis showed that those with CA125 $\leq 35 \mathrm{U} / \mathrm{mL}$ had a 1-year survival rate of $96 \%$, while those with CA125>35U/mL had a 1-year survival rate of $15 \%$ [14]. The half-life of CA125 is another widely reported indicator. In some studies, CA125 was regularly detected after surgery and chemotherapy in 225 patients with advanced ovarian cancer, and the complete remission rate of patients with serum CA125 half-life $<25 \mathrm{~d}$ was found to be 3.6 times higher than that of patients with $>25 \mathrm{~d}$ through analysis combined with the results of secondary exploration [15]. Therefore, continuous monitoring of CA125 is of great value for efficacy evaluation and prognosis analysis of ovarian cancer patients.

\section{Novel prognostic factors}

In order to develop a powerful predictive tool with both sensitivity and specificity to monitor ovarian cancer response to treatment, the research on prognostic biomarkers for ovarian cancer is continuously advancing.

\section{Blood-based prognostic biomarkers}

Blood test is minimally invasive, simple and easy to obtain specimens, and blood test results are widely used in clinic to assist the guidance of treatment. A variety of novel prognostic biomarkers derived from blood can provide a new tool for the clinical management of ovarian cancer. A total of 43 blood based biomarker studies met our selection criteria (Table 1), of which 13 were evaluated using ELISA methods for protein biomarkers [16,18-22,30-32,34,36, $37,44]$. PCR technology was used for detection of DNA or RNA source biomarkers [17,33,40-42,46,47,49, 53,54,57]. The 41 novel prognostic biomarkers provided by 43 studies can be classified by biological function, including cell proliferation and invasion [16-22], inflammatory response [23-29], angiogenesis [30-33], antioxidant [34], immune response [35-39], chemotherapeutic sensitivity [40-44], mitosis process [45], EMT (epithelial-to-mesenchymal transformation) and metastasis [46,47], deregulation of the cellular transport [48] and apoptosis process [31]. The following are representative novel prognostic factors reported in the literature.

A large number of studies have shown that chronic inflammation is closely related to the occurrence and development of cancer, and a variety of inflammatory cells and inflammatory factors participate in and promote the proliferation, invasion and metastasis of tumor cells, and affect the prognosis of patients [310]. Neutrophils and lymphocytes are both important cells involved in the inflammatory response process. The changes in the number of them can directly reflect the degree of inflammatory response in the body. NLR (neutrophil to lymphocyte ratio) is an important biological indicator of systemic inflammatory response, which can be obtained by calculating the ratio after the complete blood count [311]. Previous studies have shown that elevated NLR is an independent prognostic risk factor for several malignant tumors, including ovarian cancer [312-314]. The study of Stanislaus Argeny et al. found that the non-specific inflammatory response in cancerous tissues would lead to changes in the level of peripheral blood cells, mainly manifested as an increase in NLR. Studies have shown that neutrophils can alter the tumor microenvironment by producing cytokines and chemokines, they also promote the transformation of normal cells into tumor cells by secreting substances like reactive oxygen species and proteases. Moreover, the migration and diffusion ability of tumor cells can be enhanced by secreting platelet activating factor, matrix metalloproteinase and other factors related to tumor cell metastasis. In addition, lymphocytes are important components of the immune system and play an important role in immune surveillance. The decreased number of lymphocytes indicates the weakened immunity of the body and the reduced monitoring and killing effect on tumor cells, which cannot effectively prevent the proliferation and migration of tumor cells. Therefore, an elevated preoperative NLR usually indicates a poor prognosis in ovarian cancer patients [315]. The study of Zhang $\mathrm{H}$ et al. suggested that NLR could be used to differentiate CA125-negative ovarian cancer and was superior to CA125 in predicting patients' overall survival (OS) and progression free survival (PFS) [316]. In addition, a multivariate analysis of clinical data in 165 initial treatment ovarian cancer patients also suggested that NLR is an independent prognostic factor for PFS and OS in ovarian cancer patients [28].

Alterations in energy metabolism are a decisive biochemical feature of tumor cells, in other words, abnormal activation of glycolytic pathway still exists in tumor cells even under the condition of sufficient oxygen supply, consume large amounts of glucose and eventually produce lactic acid in order to satisfy energy supply of malignant tumor cell proliferation, this phenomenon is called aerobic glycolysis of tumors, also known as the Warburg effect [317]. In the process of glycolysis of malignant tumors, there is an important catalytic enzyme, namely lactate dehydrogenase (LDH), which mainly catalyzes the exchange of pyruvate and lactic acid, and is highly expressed in hypoxic cells, especially in tumor cells. Compared with normal tissues, the levels of glycolysis in malignant tissues were higher, and the serum LDH level of patients increased with the 
progression of the disease, especially in the advanced stage of the tumor [318]. A study shows that the LDH levels at different stages and grades differed significantly in ovarian cancer, survival curves revealed that higher $\mathrm{LDH}$ expression was correlated with shorter survival $(P<0.05)$. In addition, SATB1 may reprogram energy metabolism in ovarian cancer by regulating $\mathrm{LDH}$ and MCT1 levels to promote metastasis [319]. As another marker of tissue damage and inflammation, elevated serum LDH level can promote the proliferation, metastasis and development of cancer cells, which is commonly seen in a variety of malignant tumors [320,321]. A study showed that preoperative higher $\mathrm{LDH}$ levels were significantly associated with poor survival in patients with high grade serous ovarian cancer through survival analysis, serum high LDH levels are a promising prognostic biomarker [26].

Mesothelial protein (MSLN) is a cell surface glycoprotein, which was found by Chang et al. [322] and is usually only expressed in mesothelial tissue of body cavity. In recent years, MSLN as a differentiation antigen has been proved to be overexpressed in malignant pleural mesothelioma, pancreatic cancer, ovarian cancer and other malignant tumors, and may through increased synthesis of cyclinD1 and suppress the degradation and forming MSLN/MUC16 complex pathways involved in tumor cell proliferation, adhesion and transfer process, it is related to transcoelomic spread of ovarian cancer cells [323]. In addition, MSLN inhibits paclitaxel-induced apoptosis through serine and threonine kinase pathways, leading to chemotherapy resistance and seriously affecting the prognosis of patients [324]. The study of Karolina Okla et al. confirmed that plasma MSLN concentration in EOC patients was significantly higher than that in benign ovarian tumor patients and healthy women. Kaplan-Meier analysis results showed that, compared with low MSLN level, only high MSLN concentration of EOC patients before treatment was significantly correlated with a shorter 5 -year OS $(P=0.03)$, which predicted poor prognosis [21]. Another study showed that MSLN can enhance the invasion of ovarian cancer by inducing MMP-7 through MAPK/ERK and JNK pathways, blocking the MSLN-related pathway may be a potential strategy to improve the prognosis of ovarian cancer patients [325].

Aurora A kinase (AAK) is encoded by the Aurka gene and is a member of the serine/threonine kinase family. And as an important mitotic regulator, it can participate in many processes of cell mitosis and maintain chromosome division and spindle stability together with centrosomes [326]. Overexpression of Aurora A has been observed in a variety of malignant tumor types and plays an important regulatory role in the key control points of the tumorigenic transformation response through p53/TP53 phosphorylation [327]. Aurora A overexpression can also lead to abnormal amplification of centrosomes, leading to multilevel allocation and instability of chromosomes during division, and then to activation of oncogenes or inactivation of tumor suppressor genes [328]. Through gene chip screening and RT-PCR, the study of Hellleman et al. confirmed that Aurora A was overexpressed in ovarian cancer tissues that did not respond to platinum therapy, compared with ovarian cancer patients who responded to platinum therapy, and patients with overexpression of Aurora A had a poor prognosis [329]. A single nucleotide polymorphism in G169A at codon 57 of Aurora A locus leads to the substitution of valine by isoleucine, leading to the production of variant II. Kimura et al. [45] showed that AAK activity was reduced by the II variant, and the inhibited AAK could lead to cell death by affecting the mitosis process. Therefore, the change of single nucleotide polymorphisms in AAK may be a protective factor for cancer risk.

Galectin is an important member of the lectin superfamily, it is widely expressed in a variety of cell types and plays an important role in apoptosis, angiogenesis, cell migration, and tumor immune escape. Dysfunction or altered expression of galectin is associated with a variety of cancer types [330]. Galectin-8 and galectin-9 both have two carbohydrate recognition domains and are tandem repeat galactosins that regulate a variety of biological functions, including cell aggregation, cell adhesion, and tumor cell apoptosis [331]. Recent studies have shown that galectin-9 promotes $\mathrm{CD} 8{ }^{+} \mathrm{T}$ cell failure and induces proliferation of myeloid inhibitory cells by binding to T cell immunoglobulin mucin 3 (Tim-3), thereby participating in immune escape of tumor cells [332]. In addition, the expression of galectin-8 in solid tumors has also been proved to be closely related to tumor cell adhesion or metastasis [333]. Labrie M et al. showed that plasma Gal-8 and Gal-9 levels were significantly increased in HGSOC patients compared to healthy controls, and higher plasma galectin- 8 and galectin-9 levels were associated with a shorter 5-year disease-free survival (DFS) and 5-year OS $(P=0.005)$, multivariate analysis further demonstrated that both plasma galectin-8 and galectin- 9 could be promising biomarkers for poor prognosis in high grade serous ovarian cancer patients [171].

Angiogenesis plays an important role in tumor growth and metastasis. Neovascularization provides oxygen and nutrients to tumor cells, which can enhance cell proliferation and invasion ability [334]. 
Tumor tissue can secrete a variety of proangiogenic substances to induce and regulate angiogenesis, among which vascular endothelial growth factor (VEGF) is the primary stimulator of tumor angiogenesis. VEGF family members include VEGF-A, VEGF-B, VEGF-C, VEGF-D, etc. Among them, the biologic activity of VEGF-A is the most important, which can promote neovascularization and increase vascular permeability through VEGF/VEGFR (Vascular Endothelial Growth Factor Receptor) signaling pathway [335]. Previous studies have shown that VEGF-A is closely related to the occurrence and development of cancer and some inflammatory diseases [336]. Studies have investigated the efficacy of serum VEGF-A levels as prognostic markers in Epithelial ovarian cancer (EOC) patients, the experiment confirmed that the OS of patients with high VEGF-A level was significantly lower than that of patients with low VEGF-A level, and the difference was statistically significant $(P=0.015)$. Moreover, the VEGF-A level of patients was correlated with FIGO stage. Multivariate analysis showed that serum VEGF-A could be an independent prognostic factor for OS of patients [32]. The study of Dobrzycka B et al. showed that serum VEGF level was significantly increased in patients with serous ovarian cancer (SOC) compared with healthy control group, and higher serum VEGF level was significantly correlated with poor prognosis, and multivariate analysis confirmed that serum VEGF level was an independent risk factor for prognosis [31].

MicroRNAs (miRNAs) are a class of singlestranded small RNAs encoded by endogenous genes, which regulate the expression of target genes by acting on target mRNA to promote its degradation or inhibit its translation [337]. MiRNAs are involved in the regulation of a variety of human life activities, and studies have found that miRNAs are closely related to the occurrence and development of a variety of malignant tumors [338,339]. At present, more than $50 \%$ miRNA genes have been located in tumor-related chromosomal rearrangement regions, which have important research and application values in the diagnosis, treatment and prognosis prediction of malignant tumors. EMT is closely related to tumor invasion and metastasis, many miRNAs have been proved to directly regulate the expression of epithelial markers and indirectly regulate EMT-related growth factor signaling pathways and transcription factors to affect the EMT process [340,341]. At present, miR-200 family is the most studied miRNA related to EMT process. Gregory et al. found that TGFBeta/ZEB/miR-200 signaling pathway can regulate the transformation of cell epithelial-mesenchymal phenotype [342]. MiR-200c and miR-141 belong to the
microRNA-200 family, Gao,Y.C. et al. evaluated the value of these two miRNAs as novel prognostic biomarkers for ovarian cancer. Studies have shown that the expression levels of serum miR-200c and miR-141 in ovarian cancer patients are significantly increased compared with the normal control group, and the expression levels of the two miRNAs are correlated with different stages and pathological subtypes of ovarian cancer. Survival analysis showed that compared with the group with high serum miR-200c expression, the overall survival rate of the group with low serum miR-200c expression was significantly reduced. This is similar to the analysis results of different miR-141 expression groups, so both miR-200c and miR-141 are likely to be promising prognostic biomarkers for ovarian cancer [49]. Another study compared the expression levels of miR-200a, miR-200b and miR-200c in blood samples from 70 EOC patients and healthy controls, the results showed that these three miRNAs were significantly higher expressed in serum samples from EOC patients compared to normal controls, statistical analysis confirmed that the high expression of miR-200a, miR200b and miR-200c was significantly correlated with tumor histological subtypes, stages and lymph node metastasis, and all of them could be used as reliable indicators for predicting the prognosis of patients with EOC [46].

\section{Tissue-based prognostic biomarkers}

The overwhelming majority of selected biomarker studies investigated different tissue-based biomarkers using a variety of technical research methods. The selected tissue prognostic biomarkers can be divided into immunohistochemical biomarkers (68.77\%) [59-232], DNA biomarkers (3.95\%) [159,233-241] and RNA biomarkers (27.28\%) [242-309]. The prognostic value of 172 protein biomarkers was evaluated by immunohistochemistry in 174 studies (Table 2). These markers are classified according to their biological functions, mainly including such functional pathways as EMT and metastasis [59-71], inflammation and immunity [72-84], antioxidant [85,86], angiogenesis [87-99], cell proliferation, migration and invasion [100-116], chemotherapeutic sensitivity [117-197] and cell cycle regulation [198-201]. The remaining 79 studies of prognostic biomarkers were based on genomic DNA or RNA (Tables 3-4), involving different functional pathways in the progression of ovarian cancer, such as gene locus methylation [159,233-235], mutation status $[237,238]$, gene polymorphism $[240,241]$ and the expression of non-coding RNA during cancer cell proliferation, migration and invasion [242-282].

As a new type of anti-tumor effector 
lymphocytes with potential therapeutic value, the correlation between TIL and patient prognosis and survival has been widely concerned. Through systematic literature retrieval, we determined that TIL is a promising prognostic biomarker, and its level can be detected by immunohistochemistry. TIL can be classified by function and location in the tumor tissue, which is generally associated with better prognosis and survival, in which the presence of $\mathrm{CD} 8^{+} \mathrm{T}$ cells is positively correlated with survival [343,344]. The presence of TIL in a variety of tumor types, including metastatic melanoma, breast cancer, colorectal cancer, and ovarian cancer, has been found to be significantly correlated with patient clinical outcomes and is an important positive prognostic factor [345-349]. There is evidence that ovarian cancer patients are usually accompanied by systemic immunosuppression. In contrast, patients with a stronger immune response have improved survival and respond better to chemotherapy [350]. Mauricio P et al. [81] evaluated TIL as a prognostic survival indicator for a group of HGSOC patients, and examined the expression of matrix and intraepithelial TIL $\left(\mathrm{CD}^{+}\right.$and $\left.\mathrm{CD}^{+}\right)$in tissue samples. Multivariate analysis showed that intraepithelial $\mathrm{CD}^{+}$TIL infiltration was associated with better PFS and OS, intraepithelial CD8 ${ }^{+}$TIL infiltration was only associated with better PFS. This confirms previous studies that ovarian cancer patients with high infiltration of $\mathrm{CD}^{+}$and $\mathrm{CD} 8^{+}$TIL have better prognosis. As a new method for the treatment of ovarian cancer, the potential value of targeted immunotherapy is an important research direction, which can be used to guide clinical practice, reduce recurrence and improve the long-term survival rate of patients.

Mitochondrial superoxide dismutase (MnSOD or SOD2) is the most important antioxidant enzyme in mitochondria, which protects cells from oxidative damage induced by reactive oxygen species (ROS) and lipid peroxidation by converting endogenous superoxide to hydrogen peroxide [351]. Studies have demonstrated that SOD2 overexpression can enhance the invasion and metastasis of tumor cells by increasing the expression of matrix metalloproteinases (MMP) family members or activating Redox sensitive signaling pathways [352]. New evidence suggests that inhibition of SOD2 activity in tumor cells leads to increased apoptosis, inhibition of proliferation and increased sensitivity to chemotherapeutics [353]. There is growing evidence that SOD2 overexpression is associated with poor prognosis in a variety of cancer types, including renal clear cell carcinoma and ovarian cancer [354-356]. A study based on SOD2 immunohistochemical staining confirmed the correlation between SOD2 expression and patient prognosis in the endometriosis-associated ovarian cancer (EAOC) case group. Kaplan-Meier analysis showed that high SOD2 expression was associated with shorter PFS $(P=0.0669)$ and poorer OS $(P=0.0405)$, and increased SOD2 expression was a predictive biomarker for poor prognosis in EAOC [86].

Genome-wide analysis has confirmed that epigenetic changes are common events in many cancers, cellular genomic epigenetic disorders are important causes of many diseases, including cancer and autoimmune diseases. Epigenetic changes in human malignancies mainly include DNA methylation, nucleosomal remodeling histone modification and non-coding RNA dysregulation [357]. Numerous studies have confirmed that abnormal methylation of multiple genes involved in DNA repair, Akt /mTOR, Redox response, apoptosis, cell adhesion and cancer stem cell signaling pathways are associated with poor prognosis in ovarian cancer patients [358]. Mase et al. [235] confirmed that the DNA methylation status of ZNF671 was closely related to the recurrence and prognosis of patients with serous ovarian cancer. Multiple analysis methods combined showed that the methylation status of ZNF671 was an independent factor to predict the early recurrence of patients and patients with DNA methylation of ZNF671 had poor prognosis $(P<0.05)$. A subsequent study validated the prognostic significance of HS3ST2 methylation in patients with advanced EOC in three separate dataset of TSGH, AOCS, and TCGA, studies have confirmed that HS3ST2 inhibits the malignant phenotype of ovarian cancer by interfering with various carcinogenic ligand signals, such as IL-6, FGF2 and EGF, and patients with low HS3ST2 expression accompanied by high expression of carcinogenic cytokines or growth factors have the worst prognosis [159]. In conclusion, abnormal DNA methylation in tumor cells can be used as an effective prognostic marker for ovarian cancer. Non-coding RNA is an important part of epigenetic changes, among which long non-coding RNA (lncRNA) is an emerging regulatory RNA that is involved in the regulation of a variety of physiological and pathological processes and is abnormally expressed in a variety of types of cancers. It has been reported that the differential expression of lncRNA in ovarian cancer, lung cancer, gastric cancer and liver cancer is related to the prognosis of patients [359]. Cao $\mathrm{Y}$ et al. [265] confirmed that the expression of lncRNA CCAT1 was up-regulated in EOC tissues, and the high expression of IncRNA CCAT1 could promote the process of EMT of EOC cells, and enhance the migration and invasion ability of cells. Furthermore, high lncRNA CCAT1 expression was associated with 
FIGO stage, histological grade, lymph node metastasis and poor survival. Multivariate cox regression analysis showed that CCAT1 expression was an independent prognostic factor. In addition, it has been demonstrated that silencing of lncRNA CCAT2 in cancer cells significantly inhibits cell proliferation, migration and invasion through the Wnt/ $\beta$-catenin signaling pathway, and the results of subsequent survival analysis showed that high CCAT2 expression was associated with shorter OS or DFS, cox proportional risk regression model analysis showed that CCAT2 expression level was an independent prognostic indicator for overall survival, and these data results confirmed that lncRNA CCAT2 was a reliable prognostic marker for ovarian cancer [269].

\section{Conclusion}

Ovarian cancer is the most fatal gynecological malignancy with high incidence and low survival rate. By exploring the prognostic biomarkers associated with ovarian cancer recurrence and progression, independent risk factors affecting patient prognosis were identified, which laid a solid foundation for the development of novel treatment strategies and the improvement of patient treatment outcomes. This review searched the literature and database for the relevant reports on prognostic biomarkers of ovarian cancer, reviewed the classic clinical prognostic biomarkers, and focused on the recently discovered various prognostic markers. Advances in genomics, proteomics and metabolomics have provided favorable conditions for the discovery of novel prognostic biomarkers that have identified a variety of promising prognostic biomarkers, including miRNA, IncRNA and TIL, these biomarkers can affect the prognosis of patients through a variety of biological functional pathways. TCGA data sets and public databases can provide data information for large patient cohort genome studies, the application of bioinformatics modeling and high-throughput molecular analysis techniques has greatly enriched the knowledge related to biological processes such as cancer progression. The prognostic value of a variety of novel biomarkers was evaluated by integrating genomic, proteomic and metabolomic data and clinical information with a multivariate analysis model. The effectiveness of these novel prognostic biomarkers still needs to be further validated in large clinical trials. By studying the functional pathways of regulation of these molecular markers, the potential molecular mechanisms are revealed, so as to identify new therapeutic targets. This is a high-precision medical method, which may promote personalized treatment of ovarian cancer patients and improve their prognosis.

\section{Supplementary Material}

Supplementary materials. http://www.jcancer.org/v12p3976s1.pdf

\section{Acknowledgements}

\section{Contributions}

Shuna Liu and Ming Wu did the literature search and analysed and interpreted data. Shuna Liu wrote the manuscript. Ming $\mathrm{Wu}$ prepared the Tables and Figures. Fang Wang designed and supervised the study. We both reviewed and approved the final manuscript before submission.

\section{Competing Interests}

The authors have declared that no competing interest exists.

\section{References}

1. Siegel RL, Miller KD, Jemal A. Cancer statistics, 2020. CA Cancer J Clin. 2020 Jan;70(1):7-30.

2. Tian F, Jia L, Chu Z, Han H, Zhang Y, Cai J. MicroRNA-519a inhibits the proliferation and promotes the apoptosis of ovarian cancer cells through targeting signal transducer and activator of transcription 3. Exp Ther Med. 2018;15(2):1819-1824

3. BAKER, Vicki V. Treatment Options for Ovarian Cancer. Clinical Obstetrics \& Gynecology. 2001;44(3):522-530.

4. Clark T G, Stewart M E, Altman D G, et al. A prognostic model for ovarian cancer. British Journal of Cancer. 2001;85(7): 944-952.

5. Zheng $\mathrm{Q}$, Wang $\mathrm{P}$, Hui $\mathrm{R}$, et al. Cox regression analysis of prognostic factors in ovarian cancer patients. Cancer. 2009:16(02):99-102.

6. Jing S, Chen Z, Xie F, et al. Analysis of prognostic factors of 57 cases of ovarian cancer. Chinese Journal of Anatomy and Clinical Sciences. 2013;18(2):136-138.

7. Parmar MK, Ledermann JA, Colombo N, et al. Paclitaxel plus platinum-based chemotherapy versus conventional platinum-based chemotherapy in women with relapsed ovarian cancer: the ICON4/AGO-OVAR-2.2 trial. Lancet. 2003; 361(9375): 2099-2106.

8. Bertelsen K, Grenman S, Rustin GJ. How long should first-line chemotherapy continue? Ann Oncol. 1999;10 Suppl 1:17-20.

9. Liu C, LI Li, Zhao B, et al. III C IV stage epithelial ovarian cancer prognosis factors analysis. International Journal of Gynecology \& Obstetrics.2018;45(06):50-53+59.

10. Bast RC Jr, Feeney M, Lazarus H, Nadler LM, Colvin RB, Knapp RC. Reactivity of a monoclonal antibody with human ovarian carcinoma. J Clin Invest. 1981;68(5):1331-1337.

11. Bell J, Brady MF, Young RC, et al. Randomized phase III trial of three versus six cycles of adjuvant carboplatin and paclitaxel in early stage epithelial ovarian carcinoma: a Gynecologic Oncology Group study. Gynecol Oncol. 2006;102(3):432-439.

12. Zurawski VR Jr, Orjaseter H, Andersen A, Jellum E. Elevated serum CA 125 levels prior to diagnosis of ovarian neoplasia: relevance for early detection of ovarian cancer. Int J Cancer. 1988;42(5):677-680.

13. Redman CW, Blackledge GR, Kelly K, Powell J, Buxton EJ, Luesley DM. Early serum CA125 response and outcome in epithelial ovarian cancer. Eur J Cancer. 1990; 26(5):593-596.

14. Gadducci A, Zola P, Landoni F, et al. Serum half-life of CA 125 during early chemotherapy as an independent prognostic variable for patients with advanced epithelial ovarian cancer: results of a multicentric Italian study. Gynecol Oncol. 1995; 58(1):42-47.

15. Kato S, Abarzua-Catalan L, Trigo C, et al. Leptin stimulates migration and invasion and maintains cancer stem-like properties in ovarian cancer cells: an explanation for poor outcomes in obese women. Oncotarget. 2015;6(25):21100-21119.

16. Lyu N, Wang Y, Wang J, Zhang Z, Kong W. Study on early diagnosis of epithelial ovarian cancer by analysis of plasma septin-9 and clusterin level. J Cancer Res Ther. 2018;14(Supplement): S444-S449.

17. Meng X, Joosse SA, Müller V, et al. Diagnostic and prognostic potential of serum miR-7, miR-16, miR-25, miR-93, miR-182, miR-376a and miR-429 in ovarian cancer patients. Br J Cancer. 2015;113(9):1358-1366.

18. Cheon DJ, Li AJ, Beach JA, et al. ADAM12 is a prognostic factor associated with an aggressive molecular subtype of high-grade serous ovarian carcinoma. Carcinogenesis. 2015; 36(7):739-747. 
19. Lyu N, Wang Y, Wang J, Zhang Z, Kong W. Study on early diagnosis of epithelial ovarian cancer by analysis of plasma septin-9 and clusterin level. J Cancer Res Ther. 2018;14(Supplement): S444-S449.

20. Cymbaluk-Płoska A, Chudecka-Głaz A, Pius-Sadowska E, Machaliński B, Menkiszak J, Sompolska-Rzechuła A. Suitability assessment of baseline concentration of MMP3, TIMP3, HE4 and CA125 in the serum of patients with ovarian cancer. J Ovarian Res. 2018;11(1):1.

21. Okła K, Surówka J, Frąszczak K, et al. Assessment of the clinicopathological relevance of mesothelin level in plasma, peritoneal fluid, and tumor tissue of epithelial ovarian cancer patients. Tumour Biol. 2018;40(10):1010428318804937.

22. Jin $C$, Yang $M$, Han $X$, et al. Evaluation of the value of preoperative CYFRA21-1 in the diagnosis and prognosis of epithelial ovarian cancer in conjunction with CA125. J Ovarian Res. 2019;12(1):114.

23. Feng Z, Wen H, Bi R, et al. Preoperative Neutrophil-to-Lymphocyte Ratio as a Predictive and Prognostic Factor for High-Grade Serous Ovarian Cancer. PLoS One. 2016;11(5): e0156101.

24. Li Z, Hong N, Robertson M, Wang C, Jiang G. Preoperative red cell distribution width and neutrophil-to-lymphocyte ratio predict survival in patients with epithelial ovarian cancer. Sci Rep. 2017;7:43001.

25. Liu $\mathrm{Y}, \mathrm{Chen} \mathrm{S}$, Zheng $\mathrm{C}$, et al. The prognostic value of the preoperative c-reactive protein/albumin ratio in ovarian cancer. BMC Cancer. 2017;17(1):285

26. Pinto MP, Balmaceda C, Bravo ML, et al. Patient inflammatory status and CD4+/CD8+ intraepithelial tumor lymphocyte infiltration are predictors of outcomes in high-grade serous ovarian cancer. Gynecol Oncol. 2018;151(1):10-17.

27. Yu W, Ye Z, Fang $X$, Jiang $X$, Jiang $Y$. Preoperative albumin-to-fibrinogen ratio predicts chemotherapy resistance and prognosis in patients with advanced epithelial ovarian cancer. J Ovarian Res. 2019;12(1):88.

28. Ceran MU, Tasdemir U, Colak E, Güngör T. Can complete blood count inflammatory parameters in epithelial ovarian cancer contribute to prognosis? - a survival analysis. J Ovarian Res. 2019;12(1):16.

29. Nomelini RS, Carrijo Chiovato AF, Abdulmassih FBF, da Silva RC, Tavares-Murta BM, Murta EFC. Neutrophil-to-lymphocyte ratio and platelet count as prognostic factors in ovarian malignancies. J Cancer Res Ther. 2019;15(6):1226-1230.

30. Chen J, Liu Z, Fang S, et al. Fibulin-4 is associated with tumor progression and a poor prognosis in ovarian carcinomas. BMC Cancer. 2015;15:91.

31. Dobrzycka B, Mackowiak-Matejczyk B, Terlikowska KM, Kulesza-Bronczyk B, Kinalski M, Terlikowski SJ. Prognostic significance of pretreatment VEGF, survivin, and Smac/DIABLO serum levels in patients with serous ovarian carcinoma. Tumour Biol. 2015;36(6):4157-4165.

32. Komatsu H, Oishi T, Itamochi H, et al. Serum Vascular Endothelial Growth Factor-A as a Prognostic Biomarker for Epithelial Ovarian Cancer. Int J Gynecol Cancer. 2017;27(7):1325-1332.

33. Qiu JJ, Lin XJ, Tang XY, Zheng TT, Lin YY, Hua KQ. Exosomal Metastasis-Associated Lung Adenocarcinoma Transcript 1 Promotes Angiogenesis and Predicts Poor Prognosis in Epithelial Ovarian Cancer. Int J Biol Sci. 2018;14(14):1960-1973.

34. Pylväs-Eerola M, Karihtala $\mathrm{P}$, Puistola U. Preoperative serum 8-hydroxydeoxyguanosine is associated with chemoresistance and is a powerful prognostic factor in endometrioid-type epithelial ovarian cancer. BMC Cancer. 2015; 15: 493.

35. Hao CJ, Li J, Liu P, et al. Effects of the balance between type 1 and type $2 \mathrm{~T}$ helper cells on ovarian cancer. Genet Mol Res. 2016;15(2):10.4238/ gmr.15027936.

36. Chatterjee J, Dai W, Aziz NHA, et al. Clinical Use of Programmed Cell Death-1 and Its Ligand Expression as Discriminatory and Predictive Markers in Ovarian Cancer. Clin Cancer Res. 2017;23(13):3453-3460.

37. De La Motte Rouge T, Corné J, Cauchois A, et al. Serum CD95L Level Correlates with Tumor Immune Infiltration and Is a Positive Prognostic Marker for Advanced High-Grade Serous Ovarian Cancer. Mol Cancer Res. 2019;17(12):2537-2548.

38. Lee YJ, Chung YS, Lee JY, et al. Pretreatment lymphocytopenia is an adverse prognostic biomarker in advanced-stage ovarian cancer. Cancer Med. 2019;8(2):564-571.

39. Waki K, Kawano K, Tsuda N, Komatsu N, Yamada A. CD4/CD8 ratio is a prognostic factor in IgG nonresponders among peptide vaccine-treated ovarian cancer patients. Cancer Sci. 2020;111(4):1124-1131.

40. Konopka B, Szafron LM, Kwiatkowska E, et al. The significance of c.690G>T polymorphism (rs34529039) and expression of the CEBPA gene in ovarian cancer outcome. Oncotarget. 2016;7(41):67412-67424.

41. Feng Z, Wen H, Bi R, Duan Y, Yang W, Wu X. Thrombocytosis and hyperfibrinogenemia are predictive factors of clinical outcomes in high-grade serous ovarian cancer patients. BMC Cancer. 2016; 16: 43.

42. Chebouti I, Kuhlmann JD, Buderath P, et al. ERCC1-expressing circulating tumor cells as a potential diagnostic tool for monitoring response to platinum-based chemotherapy and for predicting post-therapeutic outcome of ovarian cancer. Oncotarget. 2017;8(15):24303-24313.

43. Fukagawa S, Miyata K, Yotsumoto F, et al. MicroRNA-135a-3p as a promising biomarker and nucleic acid therapeutic agent for ovarian cancer. Cancer Sci. 2017;108(5):886-896

44. Labrie M, De Araujo LOF, Communal L, Mes-Masson AM, St-Pierre Y. Tissue and plasma levels of galectins in patients with high grade serous ovarian carcinoma as new predictive biomarkers. Sci Rep. 2017;7(1):13244
45. Niu $\mathrm{H}$, Shin $\mathrm{H}$, Gao $\mathrm{F}$, et al. Aurora A Functional Single Nucleotide Polymorphism (SNP) Correlates With Clinical Outcome in Patients With Advanced Solid Tumors Treated With Alisertib, an Investigational Aurora A Kinase Inhibitor. EBioMedicine. 2017; 25: 50-57.

46. Zuberi M, Mir R, Das J, et al. Expression of serum miR-200a, miR-200b, and miR-200c as candidate biomarkers in epithelial ovarian cancer and their association with clinicopathological features. Clin Transl Oncol. 2015;17(10):779-787.

47. Meng X, Müller V, Milde-Langosch K, Trillsch F, Pantel K, Schwarzenbach H. Diagnostic and prognostic relevance of circulating exosomal miR-373, miR-200a, miR-200b and miR-200c in patients with epithelial ovarian cancer. Oncotarget. 2016;7(13):16923-16935.

48. Huang L, Zhou Y, Cao XP, et al. KPNA2 is a potential diagnostic serum biomarker for epithelial ovarian cancer and correlates with poor prognosis. Tumour Biol. 2017;39(6):1010428317706289.

49. Gao YC, Wu J. MicroRNA-200c and microRNA-141 as potential diagnostic and prognostic biomarkers for ovarian cancer. Tumour Biol. 2015;36(6):4843-4850.

50. Chen Y, Zhang L, Liu WX, Liu XY. Prognostic significance of preoperative anemia, leukocytosis and thrombocytosis in chinese women with epithelial ovarian cancer. Asian Pac J Cancer Prev. 2015;16(3):933-939.

51. Kurosaki A, Hasegawa $\mathrm{K}$, Kato $\mathrm{T}$, et al. Serum folate receptor alpha as a biomarker for ovarian cancer: Implications for diagnosis, prognosis and predicting its local tumor expression. Int J Cancer. 2016;138(8):1994-2002.

52. Živný JH, Leahomschi S, Klener $\mathrm{P} J \mathrm{~J}$, Živný J, Haluzík M, Cibula D. Comparison of Plasma Osteopontin Levels between Patients with Borderline Ovarian Tumours and Serous Ovarian Carcinoma. Folia Biol (Praha). 2016;62(6):258-262

53. Zuberi M, Khan I, Mir R, Gandhi G, Ray PC, Saxena A. Utility of Serum miR-125b as a Diagnostic and Prognostic Indicator and Its Alliance with a Panel of Tumor Suppressor Genes in Epithelial Ovarian Cancer. PLoS One. 2016;11(4):e0153902.

54. Zhu T, Gao W, Chen X, et al. A Pilot Study of Circulating MicroRNA-125b as a Diagnostic and Prognostic Biomarker for Epithelial Ovarian Cancer. Int J Gynecol Cancer. 2017;27(1):3-10.

55. Montavon Sartorius C, Schoetzau A, Kettelhack H, et al. ABO blood groups as a prognostic factor for recurrence in ovarian and vulvar cancer. PLoS One. 2018;13(3): e0195213.

56. He W, Zhang P, Ye M, et al. Polymorphisms of the Ras-Association Domain Family 1 Isoform A (RASSF1A) Gene are Associated with Ovarian Cancer, and with the Prognostic Factors of Grade and Stage, in Women in Southern China. Med Sci Monit. 2018; 24: 2360-2367.

57. Link T, Kuhlmann JD, Kobelt D, et al. Clinical relevance of circulating MACC1 and S100A4 transcripts for ovarian cancer. Mol Oncol. 2019;13(5):1268-1279.

58. Lu X, Li Y, Xia B, et al. Selection of small plasma peptides for the auxiliary diagnosis and prognosis of epithelial ovarian cancer by using UPLC/MS-based nontargeted and targeted analyses. Int J Cancer. 2019;144(8):2033-2042.

59. Hou M, Cheng Z, Shen $\mathrm{H}$, et al. High expression of CTHRC1 promotes EMT of epithelial ovarian cancer (EOC) and is associated with poor prognosis. Oncotarget. 2015;6(34):35813-35829

60. Prislei S, Martinelli E, Zannoni GF, et al. Role and prognostic significance of the epithelial-mesenchymal transition factor ZEB2 in ovarian cancer. Oncotarget. 2015;6(22):18966-18979.

61. Tjhay F, Motohara T, Tayama S, et al. CD44 variant 6 is correlated with peritoneal dissemination and poor prognosis in patients with advanced epithelial ovarian cancer. Cancer Sci. 2015;106(10):1421-1428.

62. Sun $\mathrm{Y}, \mathrm{Hu} \mathrm{L}$, Zheng $\mathrm{H}$, et al. MiR-506 inhibits multiple targets in the epithelial-to-mesenchymal transition network and is associated with good prognosis in epithelial ovarian cancer. J Pathol. 2015;235(1):25-36.

63. Kwon M, Kim JH, Rybak Y, et al. Reduced expression of FILIP1L, a novel WNT pathway inhibitor, is associated with poor survival, progression and chemoresistance in ovarian cancer. Oncotarget. 2016;7(47):77052-77070.

64. Nakamura H, Nagasaka K, Kawana K, et al. Expression of Par3 polarity protein correlates with poor prognosis in ovarian cancer. BMC Cancer. 2016;16(1):897.

65. Vos MC, Hollemans E, Ezendam N, et al. MMP-14 and CD44 in Epithelial-to-Mesenchymal Transition (EMT) in ovarian cancer. J Ovarian Res. 2016;9(1):53

66. Wang Y, Zhou X, Xu M, et al. OTUB1-catalyzed deubiquitination of FOXM1 facilitates tumor progression and predicts a poor prognosis in ovarian cancer. Oncotarget. 2016;7(24):36681-36697.

67. Chen L, Yao Y, Sun L, et al Snail Driving Alternative Splicing of CD44 by ESRP1 Enhances Invasion and Migration in Epithelial Ovarian Cancer. Cell Physiol Biochem. 2017;43(6):2489-2504

68. Chen Y, Wang DD, Wu YP, et al. MDM2 promotes epithelial-mesenchymal transition and metastasis of ovarian cancer SKOV3 cells. Br J Cancer. 2017;117(8):1192-1201.

69. Nakamura K, Terai Y, Tanabe A, et al. CD24 expression is a marker for predicting clinical outcome and regulates the epithelial-mesenchymal transition in ovarian cancer via both the Akt and ERK pathways. Oncol Rep. 2017;37(6):3189-3200

70. Xu Y, Zhang Q, Miao C, et al. CCNG1 (Cyclin G1) regulation by mutant-P53 via induction of Notch3 expression promotes high-grade serous ovarian cancer (HGSOC) tumorigenesis and progression. Cancer Med. 2019;8(1):351-362. 
71. Ramalho S, Andrade LAA, Filho CC, et al. Role of discoidin domain receptor 2 (DDR2) and microRNA-182 in survival of women with high-grade serous ovarian cancer. Tumour Biol. 2019;41(1):1010428318823988.

72. Knutson KL, Maurer MJ, Preston CC, et al. Regulatory T cells, inherited variation, and clinical outcome in epithelial ovarian cancer. Cancer Immunol Immunother. 2015;64(12):1495-1504.

73. Darb-Esfahani S, Kunze CA, Kulbe H, et al. Prognostic impact of programmed cell death-1 (PD-1) and PD-ligand 1 (PD-L1) expression in cancer cells and tumor-infiltrating lymphocytes in ovarian high grade serous carcinoma. Oncotarget. 2016;7(2):1486-1499.

74. Lundgren S, Berntsson J, Nodin B, Micke P, Jirström K. Prognostic impact of tumour-associated B cells and plasma cells in epithelial ovarian cancer. J Ovarian Res. 2016; 9:21.

75. James FR, Jiminez-Linan M, Alsop J, et al. Association between tumour infiltrating lymphocytes, histotype and clinical outcome in epithelial ovarian cancer. BMC Cancer. 2017;17(1):657.

76. $\mathrm{Xu} \mathrm{Y,Chen} \mathrm{L}, \mathrm{Xu} \mathrm{B}$, et al. Higher Numbers of T-Bet+ Tumor-Infiltrating Lymphocytes Associate with Better Survival in Human Epithelial Ovarian Cancer. Cell Physiol Biochem. 2017;41(2):475-483.

77. Zhu J, Wen $\mathrm{H}, \mathrm{Bi} \mathrm{R}, \mathrm{Wu} \mathrm{Y}, \mathrm{Wu} \mathrm{X}$. Prognostic value of programmed death-ligand 1 (PD-L1) expression in ovarian clear cell carcinoma. J Gynecol Oncol. 2017;28(6): e77

78. Carter JH, Deddens JA, Mueller G, et al. Transcription factors WT1 and p53 combined: a prognostic biomarker in ovarian cancer. $\mathrm{Br} \mathrm{J}$ Cancer. 2018;119(4):462-470.

79. Nakagawa S, Serada S, Kakubari R, et al. Intratumoral Delivery of an Adenoviral Vector Carrying the SOCS-1 Gene Enhances T-Cell-Mediated Antitumor Immunity By Suppressing PD-L1. Mol Cancer Ther. 2018;17(9):1941-1950.

80. Kim KH, Choi KU, Kim A, et al. PD-L1 expression on stromal tumor-infiltrating lymphocytes is a favorable prognostic factor in ovarian serous carcinoma. J Ovarian Res. 2019;12(1):56

81. Martinelli-Kläy CP, Lombardi T, Mendis B, et al. Tissue eosinophilia in oral intraepithelial neoplasia as a probable indicator of invasion. Oral Dis. 2018; 24(1-2):103-108.

82. Szubert S, Jozwicki W, Wicherek L, Koper K. Cytoplasmic and membranous receptor-binding cancer antigens expressed on SiSo cells (RCAS1) immunoreactivity in epithelial ovarian cancer cells represent differing biological function of RCAS1. Folia Histochem Cytobiol. 2019;57(3):116-126.

83. Zong L, Zhou Y, Zhang M, Chen J, Xiang Y. VISTA expression is associated with a favorable prognosis in patients with high-grade serous ovarian cancer. Cancer Immunol Immunother. 2020;69(1):33-42.

84. Jäntti T, Luhtala S, Mäenpää J, Staff S. Characterization of immunoreactivity with whole-slide imaging and digital analysis in high-grade serous ovarian cancer. Tumour Biol. 2020:42(11):1010428320971404.

85. Liew PL, Hsu CS, Liu WM, Lee YC, Lee YC, Chen CL. Prognostic and predictive values of Nrf2, Keap1, p16 and E-cadherin expression in ovarian epithelial carcinoma. Int J Clin Exp Pathol. 2015;8(5):5642-5649.

86. Amano T, Chano T, Isono T, Kimura F, Kushima R, Murakami T. Abundance of mitochondrial superoxide dismutase is a negative predictive biomarker for endometriosis-associated ovarian cancers. World J Surg Oncol. 2019;17(1):24

87. Kinose $Y$, Sawada $\mathrm{K}$, Makino $\mathrm{H}$, et al. IKK $\beta$ Regulates VEGF Expression and Is a Potential Therapeutic Target for Ovarian Cancer as an Antiangiogenic Treatment. Mol Cancer Ther. 2015;14(4):909-919.

88. Corvigno S, Wisman GB, Mezheyeuski A et al. Markers of fibroblast-rich tumor stroma and perivascular cells in serous ovarian cancer: Inter- and intra-patient heterogeneity and impact on survival. Oncotarget. 2016;7(14):18573-18584.

89. Skirnisdottir I, Seidal T, Akerud H. The relationship of the angiogenesis regulators VEGF-A, VEGF-R1 and VEGF-R2 to p53 status and prognostic factors in epithelial ovarian carcinoma in FIGO-stages I-II. Int J Oncol. 2016;48(3):998-1006.

90. Onisim A, Iancu M, Vlad C, et al. Expression of Nestin and CD133 in serous ovarian carcinoma. J BUON. 2016;21(5):1168-1175.

91. Huang $\mathrm{B}$, Yin $\mathrm{M}, \mathrm{Li}$, et al. Migration-inducing gene 7 promotes tumorigenesis and angiogenesis and independently predicts poor prognosis of epithelial ovarian cancer. Oncotarget. 2016;7(19):27552-27566.

92. Shen W, Li HL, Liu L, Cheng JX. Expression levels of PTEN, HIF-1a, and VEGF as prognostic factors in ovarian cancer. Eur Rev Med Pharmacol Sci. 2017;21(11):2596-2603

93. Yu X, Wang Y, Qiu H, et al. AEG-1 Contributes to Metastasis in HypoxiaRelated Ovarian Cancer by Modulating the HIF-1alpha/NF-kappaB/VEGF Pathway. Biomed Res Int. 2018; 2018: 3145689.

94. Chen Y, Zhang L, Liu WX, Wang K. VEGF and SEMA4D have synergistic effects on the promotion of angiogenesis in epithelial ovarian cancer. Cell Mol Biol Lett. 2018; 23: 2

95. Yang Z, Shen H, He W, et al. Expression of TBC1D16 Is Associated with Favorable Prognosis of Epithelial Ovarian Cancer. Tohoku J Exp Med. 2018;245(3):141-148.

96. Meng Q, Duan P, Li L, Miao Y. Expression of Placenta Growth Factor Is Associated with Unfavorable Prognosis of Advanced-Stage Serous Ovarian Cancer. Tohoku J Exp Med. 2018;244(4):291-296.

97. Sopo M, Anttila M, Hämäläinen $K$, et al. Expression profiles of VEGF-A, VEGF-D and VEGFR1 are higher in distant metastases than in matched primary high grade epithelial ovarian cancer. BMC Cancer. 2019;19(1):584
98. Yu L, Mao X, Jiao Y, Song W, Wang D. Zhong Nan Da Xue Xue Bao Yi Xue Ban. 2019;44(12):1344-1352

99. Sopo M, Sallinen H, Hämäläinen $K$, et al. High expression of Tie-2 predicts poor prognosis in primary high grade serous ovarian cancer. PLoS One. 2020;15(11): e0241484.

100. Cai Y, Wang J, Zhang L, et al. Expressions of fatty acid synthase and HER2 are correlated with poor prognosis of ovarian cancer. Med Oncol. 2015;32(1):391. Turcotte M, Spring K, Pommey S, et al. CD73 is associated with poor prognosis in high-grade serous ovarian cancer. Cancer Res. 2015;75(21):4494-4503.

101. Mehner C, Oberg AL, Kalli KR, et al. Serine protease inhibitor Kazal type 1 (SPINK1) drives proliferation and anoikis resistance in a subset of ovarian cancers. Oncotarget. 2015;6(34):35737-35754.

102. Zhao H, Guo E, Hu T, et al. KCNN4 and S100A14 act as predictors of recurrence in optimally debulked patients with serous ovarian cancer. Oncotarget. 2016;7(28):43924-43938

103. Xu L, Wu H, Jiang C, et al. Dacomitinib, a new pan-EGFR inhibitor, is effective in killing ovarian cancer cells. Discov Med. 2016;22(122):297-309.

104. Hu L, Liu R. Expression of Gab1 Is Associated with Poor Prognosis of Patients with Epithelial Ovarian Cancer. Tohoku J Exp Med. 2016;239(3):177-184.

105. Chang L, Guo R, Yuan Z. IL-36a suppresses proliferation of ovarian cancer cells. Tumour Biol. 2017·39(6):1010428317706918.

106. Zhang X, Liu D, Li M, et al. Prognostic and therapeutic value of disruptor of telomeric silencing-1-like (DOT1L) expression in patients with ovarian cancer. J Hematol Oncol. 2017;10(1):29.

107. Ricciardelli C, Lokman NA, Pyragius CE, et al. Keratin 5 overexpression is associated with serous ovarian cancer recurrence and chemotherapy resistance. Oncotarget. 2017;8(11):17819-17832.

108. Hiramatsu K, Serada S, Enomoto T, et al. LSR Antibody Therapy Inhibits Ovarian Epithelial Tumor Growth by Inhibiting Lipid Uptake. Cancer Res. 2018;78(2):516-527.

109. Choi $\mathrm{CH}$, Kang $\mathrm{TH}$, Song JS, et al. Elevated expression of pancreatic adenocarcinoma upregulated factor (PAUF) is associated with poor prognosis and chemoresistance in epithelial ovarian cancer. Sci Rep. 2018;8(1):12161.

110. Cao Y, Yu Y, Chen X, et al. Low Expression of Protocadherin-8 Promotes the Progression of Ovarian Cancer. Int J Gynecol Cancer. 2018;28(2):346-354.

111. Liu YB, Mei Y, Tian ZW, Long J, Luo CH, Zhou HH. Downregulation of RIF1 Enhances Sensitivity to Platinum-Based Chemotherapy in Epithelial Ovarian Cancer (EOC) by Regulating Nucleotide Excision Repair (NER) Pathway. Cell Physiol Biochem. 2018;46(5):1971-1984

112. Li M, Qian Z, Ma X, et al. MiR-628-5p decreases the tumorigenicity of epithelial ovarian cancer cells by targeting at FGFR2. Biochem Biophys Res Commun. 2018;495(2):2085-2091.

113. Han GH, Chay DB, Nam S, Cho H, Chung JY, Kim JH. Prognostic implications of forkhead box protein O1 (FOXO1) and paired box 3 (PAX3) in epithelial ovarian cancer. BMC Cancer. 2019;19(1):1202.

114. Li H, Qian Y, Wang X, Pi R, Zhao X, Wei X. Targeted activation of Stat3 in combination with paclitaxel results in increased apoptosis in epithelial ovarian cancer cells and a reduced tumour burden. Cell Prolif. 2020;53(1):e12719.

115. Liu Q, Liu H, Li L, et al. ATAD2 predicts poor outcomes in patients with ovarian cancer and is a marker of proliferation. Int J Oncol. 2020;56(1):219-231.

116. Ye $\mathrm{Q}$, Zhai $X$, Wang $W$, et al. Overexpression of Growth-Related Oncogene- $\beta$ Is Associated with Tumorigenesis, Metastasis, and Poor Prognosis in Ovarian Cancer. Dis Markers. 2015;2015:387382.

117. Zhou Y, Xu Y, Chen L, Xu B, Wu C, Jiang J. B7-H6 expression correlates with cancer progression and patient's survival in human ovarian cancer. Int J Clin Exp Pathol. 2015;8(8):9428-9433

118. Yu L, Jiao YJ, Zhou L, Song WQ, Wu SW, Wang DN. Nan Fang Yi Ke Da Xue Xue Bao. 2016;37(4):444-450.

119. Liu X, Xu Y, Jin Q, et al. EphA8 is a prognostic marker for epithelial ovarian cancer. Oncotarget. 2016;7(15):20801-20809.

120. Zhang Q, Yu S, Lam MMT, et al. Angiotensin II promotes ovarian cancer spheroid formation and metastasis by upregulation of lipid desaturation and suppression of endoplasmic reticulum stress. J Exp Clin Cancer Res. 2019;38(1):116

121. Ma Z, Wang X, He J, Xia J, Li Y. Increased expression of protein kinase CK2a correlates with poor patient prognosis in epithelial ovarian cancer. PLoS One. 2017;12(3):e0174037.

122. Zhang W, Niu C, He W, et al. Upregulation of centrosomal protein 55 is associated with unfavorable prognosis and tumor invasion in epithelial ovarian carcinoma. Tumour Biol. 2016;37(5):6239-6254

123. Manai M, Doghri R, Finetti $P$, et al. Overexpression of Annexin A1 Is an Independent Predictor of Longer Overall Survival in Epithelial Ovarian Cancer. In Vivo. 2020;34(1):177-184

124. Gruosso T, Garnier C, Abelanet S, et al. MAP3K8/TPL-2/COT is a potential predictive marker for MEK inhibitor treatment in high-grade serous ovarian carcinomas. Nat Commun. 2015;6:8583.

125. Tong $\mathrm{X}$, Barbour $\mathrm{M}, \mathrm{Hou} \mathrm{K}$, et al. Interleukin-33 predicts poor prognosis and promotes ovarian cancer cell growth and metastasis through regulating ERK and JNK signaling pathways. Mol Oncol. 2016;10(1):113-125.

126. Vlad C, Kubelac P, Onisim A, et al. Expression of CDCP1 and ADAM12 in the ovarian cancer microenvironment. J BUON. 2016:21(4):973-978.

127. Tai H, Wu Z, Sun S, Zhang Z, Xu C. FGFRL1 Promotes Ovarian Cancer Progression by Crosstalk with Hedgehog Signaling. J Immunol Res. 2018;2018:7438608. 
128. Sun $\mathrm{Q}$, Zhang $\mathrm{Y}, \mathrm{Su} \mathrm{J}, \mathrm{Li} \mathrm{T}$, Jiang $\mathrm{Y}$. Role of Hydroxysteroid Dehydrogenase-Like 2 (HSDL2) in Human Ovarian Cancer. Med Sci Monit.2018;24:3997-4008.

129. Liu W, Tian X, Ding X, Zhang L. Expression of Dual-Specificity Phosphatase 2 (DUSP2) in Patients with Serous Ovarian Carcinoma and in SKOV3 and OVCAR3 Cells In Vitro. Med Sci Monit. 2019;25:10180-10189.

130. Wu H, Li R, Zhang Z, et al. Kallistatin inhibits tumour progression and platinum resistance in high-grade serous ovarian cancer. J Ovarian Res. 2019;12(1):125.

131. Liu $\mathrm{T}$, Wei $\mathrm{Q}$, Jin J, et al. The m6A reader YTHDF1 promotes ovarian cancer progression via augmenting EIF3C translation. Nucleic Acids Res. 2020;48(7):3816-3831.

132. Isobe A, Sawada K, Kinose $Y$, et al. Interleukin 6 receptor is an independent prognostic factor and a potential therapeutic target of ovarian cancer. PLoS One. 2015;10(2):e0118080.

133. Zhang L, Wang H, Tian L, Li H. Expression of USP7 and MARCH7 Is Correlated with Poor Prognosis in Epithelial Ovarian Cancer. Tohoku J Exp Med. 2016;239(3):165-175.

134. Li H, Xiao N, Li Z, Wang Q. Expression of Inorganic Pyrophosphatase (PPA1) Correlates with Poor Prognosis of Epithelial Ovarian Cancer. Tohoku J Exp Med. 2017;241(2):165-173.

135. Zhao C, Yan M, Li C, Feng Z. POZ/BTB and AT-Hook-Containing Zinc Finger Protein 1 (PATZ1) Suppresses Progression of Ovarian Cancer and Serves as an Independent Prognosis Factor. Med Sci Monit. 2018;24:4262-4270.

136. Jiang G, Yang D, Wang L, etal. A novel biomarker ARMc8 promotes the malignant progression of ovarian cancer. Hum Pathol. 2015;46(10):1471-1479.

137. Chen L, Yao Y, Sun L, et al. Clinical implication of the serum galectin-1 expression in epithelial ovarian cancer patients. J Ovarian Res. 2015;8:78.

138. Xu Y, Wang C, Zhang Y, Jia L, Huang J. Overexpression of MAGE-A9 Is Predictive of Poor Prognosis in Epithelial Ovarian Cancer. Sci Rep. 2015;5:12104.

139. Xu N, Zhang Z, Zhu J, et al. Overexpression of trophoblast cell surface antigen 2 as an independent marker for a poor prognosis and as a potential therapeutic target in epithelial ovarian carcinoma. Int J Exp Pathol. 2016;97(2):150-158.

140. Lin TC, Chen ST, Huang MC, et al. GALNT6 expression enhances aggressive phenotypes of ovarian cancer cells by regulating EGFR activity. Oncotarget. 2017;8(26):42588-42601.

141. Schulz H, Schmoeckel E, Kuhn C, et al. Galectins-1, -3, and -7 Are Prognostic Markers for Survival of Ovarian Cancer Patients. Int J Mol Sci. 2017:18(6):1230.

142. Chang B, Meng J, Zhu H, et al. Overexpression of the recently identified oncogene REDD1 correlates with tumor progression and is an independent unfavorable prognostic factor for ovarian carcinoma. Diagn Pathol. 2018;13(1):87

143. Wang C, Wang W, Liu Y, Yong M, Yang Y, Zhou H. Rac GTPase activating protein 1 promotes oncogenic progression of epithelial ovarian cancer. Cancer Sci. 2018;109(1):84-93.

144. Koensgen D, Stope MB, Tuerbachova I, et al. Expression, Intracellular Localization, and Prognostic Value of Plasminogen Activator Inhibitor 1 and PAI-1 RNA-Binding Protein 1 in Primary and Recurrent Ovarian Cancer: A Study of the Tumor Bank Ovarian Cancer Network. Gynecol Obstet Invest. 2018;83(5):508-514

145. Sieńko J, Teliga-Czajkowska J, Przytula E, Czajkowski K, Smolarczyk R, Nowis

146. D. Peroxiredoxin-1 as a prognostic factor in patients with ovarian cancer. Ann Agric Environ Med. 2019;26(3):415-419.

147. Zeng Y, Chen M, Ganesh S, Hu S, Chen H. Clinicopathological and prognostic significance of caveolin-1 and ATG4C expression in the epithelial ovarian cancer. PLoS One. 2020;15(5):e0232235.

148. Lawrenson K, Mhawech-Fauceglia P, Worthington J, et al. Identification of novel candidate biomarkers of epithelial ovarian cancer by profiling the secretomes of three-dimensional genetic models of ovarian carcinogenesis. Int J Cancer. 2015;137(8):1806-1817.

149. Chen S, Gou WF, Zhao S, et al. The role of the REG4 gene and its encoding product in ovarian epithelial carcinoma. BMC Cancer. 2015;15:471.

150. Masoumi-Moghaddam S, Amini A, Wei AQ, Robertson G, Morris DL. Sprouty 2 protein, but not Sprouty 4 , is an independent prognostic biomarker for human epithelial ovarian cancer. Int J Cancer. 2015;137(3):560-570.

151. Abou-Taleb H, Yamaguchi K, Matsumura N, et al. Comprehensive assessment of the expression of the SWI/SNF complex defines two distinct prognostic subtypes of ovarian clear cell carcinoma. Oncotarget. 2016;7(34):54758-54770.

152. Wang $\mathrm{D}, \mathrm{Zhu} \mathrm{H}$, Ye $\mathrm{Q}$, Wang $\mathrm{C}$, Xu Y. Prognostic Value of KIF2A and HER2-Neu Overexpression in Patients With Epithelial Ovarian Cancer. Medicine (Baltimore). 2016;95(8):e2803.

153. Zhang $Q$, Chen WM, Zhang XX, et al. Overexpression of salusin- $\beta$ is associated with poor prognosis in ovarian cancer. Oncol Rep. 2017;37(3):1826-1832.

154. Song WJ, Dong Y, Luo C, Chen YY p38MAPK family isoform p38a and activating transcription factor 2 are associated with the malignant phenotypes and poor prognosis of patients with ovarian adenocarcinoma. Pathol Res Pract. 2017;213(10):1282-1288.

155. Chan KKL, Siu MKY, Jiang YX, et al. Differential expression of estrogen receptor subtypes and variants in ovarian cancer: effects on cell invasion, proliferation and prognosis. BMC Cancer. 2017;17(1):606.
156. Cheng J, Su M, Jin Y, et al. Upregulation of SENP3/SMT3IP1 promotes epithelial ovarian cancer progression and forecasts poor prognosis. Tumour Biol. 2017;39(3):1010428317694543.

157. Zhu L, Feng H, Jin S, et al. High expressions of BCL6 and Lewis y antigen are correlated with high tumor burden and poor prognosis in epithelial ovarian cancer. Tumour Biol. 2017;39(7):1010428317711655.

158. Jin C, Liu Z, Li Y, et al. PCNA-associated factor P15PAF, targeted by FOXM1, predicts poor prognosis in high-grade serous ovarian cancer patients. Int J Cancer. 2018;143(11):2973-2984.

159. Huang RL, Chen HJ, Chen LY, et al. Epigenetic loss of heparan sulfate 3-O-sulfation sensitizes ovarian carcinoma to oncogenic signals and predicts prognosis. Int J Cancer. 2018;143(8):1943-1953.

160. Sheng N, Xu YZ, Xi QH, et al. Overexpression of KIF2A is Suppressed by miR-206 and Associated with Poor Prognosis in Ovarian Cancer. Cell Physiol Biochem. 2018;50(3):810-822.

161. Wang Y, Zhou Z, Wang X, et al. TRIM59 Is a Novel Marker of Poor Prognosis and Promotes Malignant Progression of Ovarian Cancer by Inducing Annexin A2 Expression. Int J Biol Sci. 2018;14(14):2073-2082.

162. Wang L, Yan W, Li X, et al. S100A10 silencing suppresses proliferation, migration and invasion of ovarian cancer cells and enhances sensitivity to carboplatin. J Ovarian Res. 2019;12(1):113.

163. Zhou Y, Jin Z, Wang C. Glycogen phosphorylase B promotes ovarian cancer progression via Wnt/ $\beta$-catenin signaling and is regulated by miR-133a-3p. Biomed Pharmacother. 2019;120:109449.

164. Sheta R, Bachvarova M, Plante M, et al. Altered expression of different GalNAc-transferases is associated with disease progression and poor prognosis in women with high-grade serous ovarian cancer. Int J Oncol. 2017:51(6):1887-1897.

165. Ikeda Y, Park JH, Miyamoto T, et al. T-LAK Cell-Originated Protein Kinase (TOPK) as a Prognostic Factor and a Potential Therapeutic Target in Ovarian Cancer. Clin Cancer Res. 2016;22(24):6110-6117.

166. Li MJ, Li HR, Cheng X, et al. Clinical significance of targeting drug-based molecular biomarkers expression in ovarian clear cell carcinoma. Zhonghua Fu Chan Ke Za Zhi. 2017;52(12):835-843.

167. Qiu HL, Deng SZ, Li C, et al. High expression of KIF14 is associated with poor prognosis in patients with epithelial ovarian cancer. Eur Rev Med Pharmacol Sci. 2017;21(2):239-245.

168. Gao L, Ye X, Ma RQ et al. Low programmed cell death 5 expression is a prognostic factor in ovarian cancer. Chin Med J (Engl). 2015;128(8):1084-1090.

169. Makii C, Oda K, Ikeda Y, et al. MDM2 is a potential therapeutic target and prognostic factor for ovarian clear cell carcinomas with wild type TP53. Oncotarget. 2016;7(46):75328-75338.

170. Shin K, Kim KH, Yoon MS, et al. Expression of Interactive Genes Associated with Apoptosis and Their Prognostic Value for Ovarian Serous Adenocarcinoma. Adv Clin Exp Med. 2016;25(3):513-521.

171. Labrie M, De Araujo LOF, Communal L, Mes-Masson AM, St-Pierre Y. Tissue and plasma levels of galectins in patients with high grade serous ovarian carcinoma as new predictive biomarkers. Sci Rep. 2017;7(1):13244.

172. Lee YK, Chung HH, Kim JW, Song YS, Park NH. Expression of phosphorylated Akt and hTERT is associated with prognosis of epithelial ovarian carcinoma. Int J Clin Exp Pathol. 2015;8(11):14971-14976.

173. Wang L, Wang C, Jin S, Qu D, Ying H. Expression of NF-kB and PTEN in primary epithelial ovarian carcinoma and the correlation with chemoresistance. Int J Clin Exp Pathol. 2015;8(9):10953-10963.

174. Ayub TH, Keyver-Paik MD, Debald M, et al. Accumulation of ALDH1-positive cells after neoadjuvant chemotherapy predicts treatment resistance and prognosticates poor outcome in ovarian cancer. Oncotarget. 2015;6(18):16437-16448

175. Corkery DP, Le Page C, Meunier L, Provencher D, Mes-Masson AM, Dellaire G. PRP4K is a HER2-regulated modifier of taxane sensitivity. Cell Cycle. 2015;14(7):1059-1069.

176. Miyamoto $M$, Takano M, Iwaya K, et al. High-temperature-required protein $\mathrm{A} 2$ as a predictive marker for response to chemotherapy and prognosis in patients with high-grade serous ovarian cancers. Br J Cancer. 2017;116(6):e2.

177. Wang L, Wang C, Jin S, Qu D, Ying H. Expression of NF-kB and PTEN in primary epithelial ovarian carcinoma and the correlation with chemoresistance. Int J Clin Exp Pathol. 2015;8(9):10953-10963.

178. Zhang Y, Yu JJ, Tian Y, et al. eIF3a improve cisplatin sensitivity in ovarian cancer by regulating XPC and p27Kip1 translation. Oncotarget. 2015;6(28):25441-25451.

179. Gayarre J, Kamieniak MM, Cazorla-Jiménez A, et al. The NER-related gene GTF2H5 predicts survival in high-grade serous ovarian cancer patients. J Gynecol Oncol. 2016;27(1):e7.

180. Sung PL, Jan YH, Lin SC, et al. Periostin in tumor microenvironment is associated with poor prognosis and platinum resistance in epithelial ovarian carcinoma. Oncotarget. 2016;7(4):4036-4047.

181. Kwon AY, Heo I, Lee HJ, et al. Sox10 expression in ovarian epithelial tumors is associated with poor overall survival. Virchows Arch. 2016;468(5):597-605.

182. He S, Niu G, Shang J, et al. The oncogenic Golgi phosphoprotein 3 like overexpression is associated with cisplatin resistance in ovarian carcinoma and activating the NF-kB signaling pathway. J Exp Clin Cancer Res. 2017;36(1):137. 
183. Miyamoto M, Takano M, Aoyama T, et al. Inhibition of autophagy protein LC3A as a therapeutic target in ovarian clear cell carcinomas. J Gynecol Oncol. 2017;28(3):e33

184. Sun X, Zhang W, Li H, et al. Stonin 2 Overexpression is Correlated with Unfavorable Prognosis and Tumor Invasion in Epithelial Ovarian Cancer. Int J Mol Sci. 2017;18(8):1653.

185. Chen HJ, Huang RL, Liew PL, et al. GATA3 as a master regulator and therapeutic target in ovarian high-grade serous carcinoma stem cells. Int J Cancer. 2018;143(12):3106-3119.

186. Zhang X, Li H, Yu X, et al. Analysis of Circulating Tumor Cells in Ovarian Cancer and Their Clinical Value as a Biomarker. Cell Physiol Biochem. 2018;48(5):1983-1994

187. Zhang X, Feng Y, Wang XY, et al. The inhibition of UBC13 expression and blockage of the DNMT1-CHFR-Aurora A pathway contribute to paclitaxel resistance in ovarian cancer. Cell Death Dis. 2018;9(2):93.

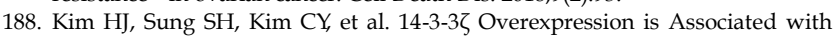
Poor Prognosis in Ovarian Cancer. Yonsei Med J. 2018;59(1):51-56.

189. Liu X, Wei L, Zhao B, Cai X, Dong C, Yin F. Low expression of KCNN3 may affect drug resistance in ovarian cancer. Mol Med Rep. 2018;18(2):1377-1386.

190. Long J, Zhu JY, Liu YB, et al. Helicase POLQ-like (HELQ) as a novel indicator of platinum-based chemoresistance for epithelial ovarian cancer. Gynecol Oncol. 2018;149(2):341-349.

191. Jin C, Liu Z, Li Y, et al. PCNA-associated factor P15PAF, targeted by FOXM1, predicts poor prognosis in high-grade serous ovarian cancer patients. Int J Cancer. 2018;143(11):2973-2984.

192. Fu Z, Wang C, Chen Y, Zhang X, Wang X, Xie X. Down-regulation of UTP23 promotes paclitaxel resistance and predicts poorer prognosis in ovarian cancer. Pathol Res Pract. 2019;215(11):152625.

193. Hou L, Zhang X, Jiao Y, et al. ATP binding cassette subfamily B member 9 (ABCB9) is a prognostic indicator of overall survival in ovarian cancer. Medicine (Baltimore). 2019;98(19):e15698.

194. Ma H, Li Y, Wang X, et al. PBK, targeted by EVI1, promotes metastasis and confers cisplatin resistance through inducing autophagy in high-grade serous ovarian carcinoma. Cell Death Dis. 2019;10(3):166.

195. Zhang S, Deng M, Wang Q, Jiang Y, Xu Q, Cao L. Level of Sorcin expression influences chemoresistance and overall survival in patients with ovarian cancer. Zhong Nan Da Xue Xue Bao Yi Xue Ban. 2019;44(10):1113-1119.

196. Bu H, Li Y, Jin C, et al. Overexpression of PRC1 indicates a poor prognosis in ovarian cancer. Int J Oncol. 2020;56(3):685-696.

197. Feng LY, Li L. Low expression of NCALD is associated with chemotherapy resistance and poor prognosis in epithelial ovarian cancer. J Ovarian Res. 2020;13(1):35.

198. Hua M, Yan S, Deng Y, et al. CAP1 is overexpressed in human epithelial ovarian cancer and promotes cell proliferation. Int J Mol Med. 2015;35(4):941-949.

199. Ayhan A, Kuhn E, Wu RC, et al. CCNE1 copy-number gain and overexpression identify ovarian clear cell carcinoma with a poor prognosis. Mod Pathol. 2017;30(2):297-303.

200. Shi C, Qin L, Gao H, et al. NUCKS nuclear elevated expression indicates progression and prognosis of ovarian cancer. Tumour Biol. 2017;39(9):1010428317714631.

201. Wang J, Liu Q, Zhou X, et al. Thymidine kinase 1 expression in ovarian serous adenocarcinoma is superior to Ki-67: A new prognostic biomarker. Tumour Biol. 2017;39(6):1010428317706479.

202. Doghri R, Manai M, Finetti P, et al. Stromal Expression of MARCKS Protein in Ovarian Carcinomas Has Unfavorable Prognostic Value. Int J Mol Sci. 2017;19(1):41.

203. Horikawa N, Abiko K, Matsumura N, et al. Expression of Vascular Endothelial Growth Factor in Ovarian Cancer Inhibits Tumor Immunity through the Accumulation of Myeloid-Derived Suppressor Cells. Clin Cancer Res. 2017;23(2):587-599

204. Chen M, Sheng XJ, Qin YY, et al. TBC1D8 Amplification Drives Tumorigenesis through Metabolism Reprogramming in Ovarian Cancer. Theranostics. 2019;9(3):676-690.

205. Feng Y, Tang Y, Mao Y, et al. PAX2 promotes epithelial ovarian cancer progression involving fatty acid metabolic reprogramming. Int $\mathrm{J}$ Oncol. 2020;56(3):697-708

206. Hedström E, Pederiva C, Farnebo J, et al. Downregulation of the cancer susceptibility protein WRAP53 $\beta$ in epithelial ovarian cancer leads to defective DNA repair and poor clinical outcome. Cell Death Dis. 2015;6(10):e1892.

207. Mei L, Hu Q, Peng J, et al. Phospho-histone H2AX is a diagnostic and prognostic marker for epithelial ovarian cancer. Int J Clin Exp Pathol. 2015;8(5):5597-5602.

208. Sun F, Ding W, He JH, Wang XJ, Ma ZB, Li YF. Stomatin-like protein 2 is overexpressed in epithelial ovarian cancer and predicts poor patient survival. BMC Cancer. 2015;15:746.

209. Sosulski A, Horn H, Zhang L, et al. CD44 Splice Variant v8-10 as a Marker of Serous Ovarian Cancer Prognosis. PLoS One. 2016;11(6):e0156595.

210. Zuo J, Song Y, Li Z, Wu LY. Relationship between P53 Protein Expression and Prognosis of Advanced Ovarian Serous Adenocarcinoma. Zhongguo Yi Xue Ke Xue Yuan Xue Bao. 2016;38(2):169-174.

211. van der Steen SC, van Tilborg AA, Vallen MJ, Bulten J, van Kuppevelt TH, Massuger LF. Prognostic significance of highly sulfated chondroitin sulfates in ovarian cancer defined by the single chain antibody GD3A11. Gynecol Oncol. 2016;140(3):527-536.
212. Li X, Yu Z, Fang L, Liu F, Jiang K. Expression of Adiponectin Receptor-1 and Prognosis of Epithelial Ovarian Cancer Patients. Med Sci Monit. 2017;23:1514-1521.

213. Rzepecka IK, Szafron LM, Stys A, et al. Prognosis of patients with BRCA1-associated ovarian carcinomas depends on TP53 accumulation status in tumor cells. Gynecol Oncol. 2017;144(2):369-376.

214. Sakr S, Abdulfatah E, Thomas S, et al. Granulosa Cell Tumors: Novel Predictors of Recurrence in Early-stage Patients. Int J Gynecol Pathol. 2017;36(3):240-252.

215. Tian X, Han Y, Yu L, et al. Decreased expression of ALDH5A1 predicts prognosis in patients with ovarian cancer. Cancer Biol Ther. 2017;18(4):245-251.

216. Veneris JT, Darcy KM, Mhawech-Fauceglia P, et al. High glucocorticoid receptor expression predicts short progression-free survival in ovarian cancer. Gynecol Oncol. 2017;146(1):153-160.

217. Wang D, Cao X, Zhang Y, et al. LAMP3 expression correlated with poor clinical outcome in human ovarian cancer. Tumour Biol. 2017;39(3):1010428317695014.

218. Wang Y, Sun J, Li N, et al. HBXIP overexpression is correlated with the clinical features and survival outcome of ovarian cancer. J Ovarian Res. 2017;10(1):26.

219. Yasuda K, Hirohashi Y, Mariya T, et al. Phosphorylation of HSF1 at serine 326 residue is related to the maintenance of gynecologic cancer stem cells through expression of HSP27. Oncotarget. 2017;8(19):31540-31553.

220. Beeghly-Fadiel A, Wilson AJ, Keene S, et al. Differential cyclooxygenase expression levels and survival associations in type I and type II ovarian tumors. J Ovarian Res. 2018;11(1):17.

221. Zhu CX, Xiong W, Wang ML, et al. Nuclear G protein-coupled oestrogen receptor (GPR30) predicts poor survival in patients with ovarian cancer. J Int Med Res. 2018;46(2):723-731.

222. Li L, Li X, Meng Q, Khan AQ, Chen X. Increased Expression of Holliday Junction-Recognizing Protein (HJURP) as an Independent Prognostic Biomarker in Advanced-Stage Serous Ovarian Carcinoma. Med Sci Monit. 2018;24:3050-3055.

223. Schulz H, Kuhn C, Hofmann S, et al. Overall Survival of Ovarian Cancer Patients Is Determined by Expression of Galectins-8 and -9. Int J Mol Sci. 2018;19(1):323

224. Chung YW, Kim S, Hong JH, et al. Overexpression of HER2/HER3 and clinical feature of ovarian cancer. J Gynecol Oncol. 2019;30(5):e75.

225. Gou R, Zhu L, Zheng M, et al. Annexin A8 can serve as potential prognostic biomarker and therapeutic target for ovarian cancer: based on the comprehensive analysis of Annexins. J Transl Med. 2019;17(1):275.

226. Han GH, Chay DB, Yi JM, Cho H, Chung JY, Kim JH. Loss of Both USP10 and p14ARF Protein Expression Is an Independent Prognostic Biomarker for Poor Prognosis in Patients With Epithelial Ovarian Cancer. Cancer Genomics Proteomics. 2019;16(6):553-562.

227. Qian H, Yuan D, Bao J, et al. Increased expression of plakophilin 3 is associated with poor prognosis in ovarian cancer. Medicine (Baltimore). 2019;98(10):e14608

228. Szubert S, Moszynski R, Szpurek D, et al. The expression of Platelet-derived Growth factor receptors (PDGFRs) and their correlation with overall survival of patients with ovarian cancer. Ginekol Pol. 2019:90(5):242-249.

229. Xin B, Ji KQ, Liu YS, Zhao XD. Higher expression of calcineurin predicts poor prognosis in unique subtype of ovarian cancer. J Ovarian Res. 2019;12(1):75.

230. Xu L, Guo Y, Xu N, et al. Overexpression of thymic stromal lymphopoietin is correlated with poor prognosis in epithelial ovarian carcinoma. Biosci Rep. 2019;39(5): BSR20190116.

231. Zhang L, Sun L, Zhang B, Chen L. Identification of Differentially Expressed Genes (DEGs) Relevant to Prognosis of Ovarian Cancer by Use of Integrated Bioinformatics Analysis and Validation by Immunohistochemistry Assay. Med Sci Monit.2019;25:9902-9912.

232. Czogalla B, Deuster E, Liao Y, et al. Cytoplasmic VDR expression as an independent risk factor for ovarian cancer. Histochem Cell Biol. 2020;154(4):421-429.

233. Phelps DL, Borley JV, Flower KJ, et al. Methylation of MYLK3 gene promoter region: a biomarker to stratify surgical care in ovarian cancer in a multicentre study. Br J Cancer. 2017;116(10):1287-1293.

234. Bubancova I, Kovarikova H, Laco J, et al. Next-Generation Sequencing Approach in Methylation Analysis of HNF1B and GATA4 Genes: Searching for Biomarkers in Ovarian Cancer. Int J Mol Sci. 2017;18(2):474.

235. Mase S, Shinjo K, Totani H, et al. ZNF671 DNA methylation as a molecular predictor for the early recurrence of serous ovarian cancer. Cancer Sci. 2019;110(3):1105-1116.

236. Nielsen B, Kleppe A, Hveem TS, et al. Association Between Proportion of Nuclei With High Chromatin Entropy and Prognosis in Gynecological Cancers. J Natl Cancer Inst. 2018;110(12):1400-1408.

237. Eoh KJ, Park HS, Park JS, et al. Comparison of Clinical Outcomes of BRCA1/2 Pathologic Mutation, Variants of Unknown Significance, or Wild Type Epithelial Ovarian Cancer Patients. Cancer Res Treat. 2017;49(2):408-415.

238. Kim SI, Lee M, Kim HS, et al. Effect of BRCA mutational status on survival outcome in advanced-stage high-grade serous ovarian cancer. J Ovarian Res. 2019;12(1):40.

239. Kalavska K, Minarik T, Vlkova B, et al. Prognostic value of various subtypes of extracellular DNA in ovarian cancer patients. J Ovarian Res. 2018;11(1):85.

240. Liu J, Liu T, Liang L, et al. Clinical relationships between the rs2212020 and rs189897 polymorphisms of the ITGA9 gene and epithelial ovarian cancer. J Genet. 2019;98:28. 
241. Zhang Y, Wang Y, Huang X, et al. Association between AXIN1 gene polymorphisms and epithelial ovarian cancer in Chinese population. Biomark Med. 2019;13(6):445-455.

242. Cong J, Liu R, Wang X, Wang J, Wang H, Hou J. Low miR-498 expression levels are associated with poor prognosis in ovarian cancer. Eur Rev Med Pharmacol Sci. 2015;19(24):4762-4765.

243. Li H, Xu Y, Qiu W, Zhao D, Zhang Y. Tissue miR-193b as a Novel Biomarker for Patients with Ovarian Cancer. Med Sci Monit. 2015;21:3929-3934.

244. Zhang X, Liu J, Zang D, et al. Upregulation of miR-572 transcriptionally suppresses SOCS1 and p21 and contributes to human ovarian cancer progression. Oncotarget. 2015;6(17):15180-15193.

245. Ying L, Zhang F, Pan X, et al. Complement component 7 (C7), a potential tumor suppressor, is correlated with tumor progression and prognosis. Oncotarget. 2016;7(52):86536-86546

246. Shang AQ, Wu J, Bi F, et al. Relationship between HER2 and JAK/STAT-SOCS3 signaling pathway and clinicopathological features and prognosis of ovarian cancer. Cancer Biol Ther. 2017;18(5):314-322.

247. Zhang X, Liu G, Qiu J, Zhang N, Ding J, Hua K. E2F1-regulated long non-coding RNA RAD51-AS1 promotes cell cycle progression, inhibits apoptosis and predicts poor prognosis in epithelial ovarian cancer. Sci Rep. 2017;7(1):4469.

248. Chen P, Fang X, Xia B, Zhao Y, Li Q, Wu X. Long noncoding RNA LINC00152 promotes cell proliferation through competitively binding endogenous miR-125b with MCL-1 by regulating mitochondrial apoptosis pathways in ovarian cancer. Cancer Med. 2018;7(9):4530-4541.

249. Guo TY, Xu HY, Chen WJ, Wu MX, Dai X. Downregulation of miR-1294 associates with prognosis and tumor progression in epithelial ovarian cancer. Eur Rev Med Pharmacol Sci. 2018;22(22):7646-7652.

250. Li TH, Zhang JJ, Liu SX, Chen Y. Long non-coding RNA taurine-upregulated gene 1 predicts unfavorable prognosis, promotes cells proliferation, and inhibits cells apoptosis in epithelial ovarian cancer. Medicine (Baltimore). 2018;97(19):e0575.

251. Liu J, Gu Z, Tang Y, Hao J, Zhang C, Yang X. Tumour-suppressive microRNA-424-5p directly targets CCNE1 as potential prognostic markers in epithelial ovarian cancer. Cell Cycle. 2018;17(3):309-318.

252. Zhao L, Ji G, Le X, et al. Long Noncoding RNA LINC00092 Acts in Cancer-Associated Fibroblasts to Drive Glycolysis and Progression of Ovarian Cancer. Cancer Res. 2017;77(6):1369-1382.

253. Ren XY, Yang WB, Tian Y. Overexpression of long noncoding RNA PTPRG-AS1 is associated with poor prognosis in epithelial ovarian cancer. Rev Assoc Med Bras (1992). 2020;66(7):948-953.

254. Chen ZJ, Zhang Z, Xie BB, Zhang HY. Clinical significance of up-regulated IncRNA NEAT1 in prognosis of ovarian cancer. Eur Rev Med Pharmacol Sci. 2016;20(16):3373-3377.

255. Fu Y, Biglia N, Wang Z, et al. Long non-coding RNAs, ASAP1-IT1, FAM215A and LINC00472, in epithelial ovarian cancer. Gynecol Oncol. 2016;143(3):642-649.

256. Kim TH, Song JY, Park H, et al. miR-145, targeting high-mobility group A2, is a powerful predictor of patient outcome in ovarian carcinoma. Cancer Lett. 2015;356(2 Pt B):937-945

257. Fan Y, Fan J, Huang L, et al. Increased expression of microRNA-196a predicts poor prognosis in human ovarian carcinoma. Int J Clin Exp Pathol. 2015;8(4):4132-4137.

258. Zhao W, Han T, Li B, Ma Q, Yang P, Li H. miR-552 promotes ovarian cancer progression by regulating PTEN pathway. J Ovarian Res. 2019;12(1):121

259. Cheng Z, Guo J, Chen L, Luo N, Yang W, Qu X. A long noncoding RNA AB073614 promotes tumorigenesis and predicts poor prognosis in ovarian cancer. Oncotarget. 2015;6(28):25381-25389.

260. Ma M, Yu N. Over-Expression of TBL1XR1 Indicates Poor Prognosis of Serous Epithelial Ovarian Cancer. Tohoku J Exp Med. 2017;241(3):239-247.

261. Li AH, Zhang HH. Overexpression of IncRNA MNX1-AS1 is associated with poor clinical outcome in epithelial ovarian cancer. Eur Rev Med Pharmacol Sci. 2017;21(24):5618-5623.

262. Yong W, Yu D, Jun Z, et al. Long noncoding RNA NEAT1, regulated by LIN28B, promotes cell proliferation and migration through sponging miR-506 in high-grade serous ovarian cancer. Cell Death Dis. 2018;9(9):861.

263. Wei H, Tang QL, Zhang K, Sun JJ, Ding RF. miR-532-5p is a prognostic marker and suppresses cells proliferation and invasion by targeting TWIST1 in epithelial ovarian cancer. Eur Rev Med Pharmacol Sci. 2018;22(18):5842-5850.

264. Qiu JJ, Lin YY, Ding JX, Feng WW, Jin HY, Hua KQ. Long non-coding RNA ANRIL predicts poor prognosis and promotes invasion/metastasis in serous ovarian cancer. Int J Oncol. 2015;46(6):2497-2505.

265. Cao Y, Shi H, Ren F, Jia Y, Zhang R. Long non-coding RNA CCAT1 promotes metastasis and poor prognosis in epithelial ovarian cancer. Exp Cell Res. 2017;359(1):185-194.

266. Mei J, Huang Y, Hao L, et al. DAAM1-mediated migration and invasion of ovarian cancer cells are suppressed by miR-208a-5p. Pathol Res Pract. 2019;215(7):152452

267. Chen $X$, Huang J, Lü Y.High expression of STAT2 in ovarian cancer and its effect on metastasis of ovarian cancer cells. Nan Fang Yi Ke Da Xue Xue Bao. 2020;40(1):34-41

268. Zhu D, Huang X, Liang F, Zhao L. LncRNA miR503HG interacts with miR-31-5p through multiple ways to regulate cancer cell invasion and migration in ovarian cancer. J Ovarian Res. 2020;13(1):3.
269. Huang S, Qing C, Huang Z, Zhu Y. The long non-coding RNA CCAT2 is up-regulated in ovarian cancer and associated with poor prognosis. Diagn Pathol. 2016;11(1):49.

270. Sun J, Yang $X$, Zhang R, et al. GOLPH3 induces epithelial-mesenchymal transition via $W n t / \beta$-catenin signaling pathway in epithelial ovarian cancer. Cancer Med. 2017;6(4):834-844

271. Yim GW, Kim HJ, Kim LK, et al. Long Non-coding RNA HOXA11 Antisense Promotes Cell Proliferation and Invasion and Predicts Patient Prognosis in Serous Ovarian Cancer. Cancer Res Treat. 2017;49(3):656-668.

272. Zhang J, Liu W, Shen F, et al. The activation of microRNA-520h-associated TGF- $\beta 1 / \mathrm{c}-\mathrm{Myb} / \mathrm{Smad} 7$ axis promotes epithelial ovarian cancer progression. Cell Death Dis. 2018;9(9):884.

273. Yang XS, Wang GX, Luo L. Long non-coding RNA SNHG16 promotes cell growth and metastasis in ovarian cancer. Eur Rev Med Pharmacol Sci. 2018;22(3):616-622

274. Xu QF, Tang YX, Wang X. LncRNA EBIC promoted proliferation, metastasis and cisplatin resistance of ovarian cancer cells and predicted poor survival in ovarian cancer patients. Eur Rev Med Pharmacol Sci. 2018;22(14):4440-4447.

275. Guo C, Wang X, Chen LP, et al. Long non-coding RNA MALAT1 regulates ovarian cancer cell proliferation, migration and apoptosis through Wnt/ $\beta$-catenin signaling pathway. Eur Rev Med Pharmacol Sci. 2018;22(12):3703-3712.

276. Huang K, Geng J, Wang J. Long non-coding RNA RP11-552M11.4 promotes cells proliferation, migration and invasion by targeting BRCA2 in ovarian cancer. Cancer Sci. 2018;109(5):1428-1446.

277. Wang S, Ning Y, Wei P, et al. The non-coding RNA OTUB1-isoform2 promotes ovarian tumour progression and predicts poor prognosis. J Cell Mol Med. 2018;22(10):4794-4806.

278. Li X, Zhang NX, Ye HY, et al. HYOU1 promotes cell growth and metastasis via activating PI3K/AKT signaling in epithelial ovarian cancer and predicts poor prognosis. Eur Rev Med Pharmacol Sci. 2019;23(10):4126-4135.

279. Liu HY, Zhang YY, Zhu BL, et al. MiR-203a-3p regulates the biological behaviors of ovarian cancer cells through mediating the Akt/GSK-3 $\beta /$ Snail signaling pathway by targeting ATM. J Ovarian Res. 2019;12(1):60.

280. Pan L, Meng Q, Li H, Liang K, Li B. LINC00339 promotes cell proliferation, migration, and invasion of ovarian cancer cells via miR-148a-3p/ROCK1 axes. Biomed Pharmacother. 2019;120:109423.

281. Wang D, Dai J, Hou S, Qian Y. LncRNA SNHG20 predicts a poor prognosis and promotes cell progression in epithelial ovarian cancer. Biosci Rep. 2019;39(4):BSR20182186.

282. Zhao LW, Yu AJ, Zhang YJ, Wang XC, Han B, Wang XH. MicroRNA-149 suppresses the malignant phenotypes of ovarian cancer via downregulation of MSI2 and inhibition of PI3K/AKT pathway. Eur Rev Med Pharmacol Sci. 2020;24(1):55-64.

283. Liu G, Xue F, Zhang W. miR-506: a regulator of chemo-sensitivity through suppression of the RAD51-homologous recombination axis. Chin J Cancer. 2015;34(11):485-487.

284. Chiang YC, Lin HW, Chang CF, et al Overexpression of CHI3L1 is associated with chemoresistance and poor outcome of epithelial ovarian carcinoma. Oncotarget. 2015;6(37):39740-39755

285. Hsu KF, Shen MR, Huang YF, et al. Overexpression of the RNA-binding proteins Lin28B and IGF2BP3 (IMP3) is associated with chemoresistance and poor disease outcome in ovarian cancer. Br J Cancer. 2015;113(3):414-424.

286. Kritsch D, Hoffmann F, Steinbach D, et al. Tribbles 2 mediates cisplatin sensitivity and DNA damage response in epithelial ovarian cancer. Int J Cancer. 2017;141(8):1600-1614.

287. Xiao M, Cai J, Cai L, et al. Let-7e sensitizes epithelial ovarian cancer to cisplatin through repressing DNA double strand break repair. J Ovarian Res. 2017;10(1):24.

288. Zanotti L, Romani C, Tassone L, et al. MAL gene overexpression as a marker of high-grade serous ovarian carcinoma stem-like cells that predicts chemoresistance and poor prognosis. BMC Cancer. 2017:17(1):366.

289. Wang Y, Bao W, Liu Y, et al. miR-98-5p contributes to cisplatin resistance in epithelial ovarian cancer by suppressing miR-152 biogenesis via targeting Dicer1. Cell Death Dis. 2018;9(5):447.

290. Gu ZW, He YF, Wang WJ, Tian Q, Di W. MiR-1180 from bone marrow-derived mesenchymal stem cells induces glycolysis and chemoresistance in ovarian cancer cells by upregulating the Wnt signaling pathway. J Zhejiang Univ Sci B. 2019:20(3):219-237.

291. Long $\mathrm{X}$, Song $\mathrm{K}, \mathrm{Hu} \mathrm{H}$, et al. Long non-coding RNA GAS5 inhibits DDP-resistance and tumor progression of epithelial ovarian cancer via GAS5-E2F4-PARP1-MAPK axis. J Exp Clin Cancer Res. 2019;38(1):345.

292. Leonard B, Starrett GJ, Maurer MJ, et al. APOBEC3G Expression Correlates with T-Cell Infiltration and Improved Clinical Outcomes in High-grade Serous Ovarian Carcinoma. Clin Cancer Res. 2016;22(18):4746-4755.

293. Colvin EK, Howell VM, Mok SC, Samimi G, Vafaee F. Expression of long noncoding RNAs in cancer-associated fibroblasts linked to patient survival in ovarian cancer. Cancer Sci. 2020;111(5):1805-1817.

294. Liu TT, $\mathrm{Xu} \mathrm{H}$, Gao WP, et al. SET and MYND Domain-Containing Protein 3 (SMYD3) Polymorphism as a Risk Factor for Susceptibility and Poor Prognosis in Ovarian Cancer. Med Sci Monit.2016;22:5131-5140.

295. Wang YS, Ma LN, Sun JX, Liu N, Wang H. Long non-coding RNA CPS1-IT1 is a positive prognostic factor and inhibits epithelial ovarian cancer tumorigenesis. Eur Rev Med Pharmacol Sci. 2017;21(14):3169-3175. 
296. Szafron LM, Balcerak A, Grzybowska EA, et al. The putative oncogene, CRNDE, is a negative prognostic factor in ovarian cancer patients. Oncotarget. 2015;6(41):43897-43910.

297. Yuan C, Liu X, Liu X, et al. The GADD45A (1506T $>$ C) Polymorphism Is Associated with Ovarian Cancer Susceptibility and Prognosis. PLoS One. 2015;10(9):e0138692.

298. Zhang X, Guo G, Wang G, et al. Profile of differentially expressed miRNAs in high-grade serous carcinoma and clear cell ovarian carcinoma, and the expression of miR-510 in ovarian carcinoma. Mol Med Rep. 2015;12(6):8021-8031.

299. Lu L, Katsaros D, Canuto EM, Biglia N, Risch HA, Yu H. LIN-28B/let-7a/IGF-II axis molecular subtypes are associated with epithelial ovarian cancer prognosis. Gynecol Oncol. 2016;141(1):121-127.

300. Halvorsen AR, Kristensen G, Embleton A, et al. Evaluation of Prognostic and Predictive Significance of Circulating MicroRNAs in Ovarian Cancer Patients. Dis Markers. 2017;2017:3098542.

301. Zhou QH, Zhao YM, Jia LL, Zhang Y. Mir-595 is a significant indicator of poor patient prognosis in epithelial ovarian cancer. Eur Rev Med Pharmacol Sci. 2017;21(19):4278-4282.

302. Geng X, Liu Y, Diersch S, et al. Clinical relevance of kallikrein-related peptidase 9, 10, 11, and 15 mRNA expression in advanced high-grade serous ovarian cancer. PLoS One. 2017;12(11):e0186847.

303. Ai H, Xie W, Xiu AH, et al. The down-regulation of long non-coding RNA LINC01088 is associated with the poor prognosis of epithelial ovarian cancer patients. Eur Rev Med Pharmacol Sci. 2018;22(18):5836-5841.

304. Chu ZP, Dai J, Jia LG, et al. Increased expression of long noncoding RNA HMMR-AS1 in epithelial ovarian cancer: an independent prognostic factor. Eur Rev Med Pharmacol Sci. 2018;22(23):8145-8150.

305. Zou T, Wang PL, Gao Y, Liang WT. Circular RNA_LARP4 is lower expressed and serves as a potential biomarker of ovarian cancer prognosis. Eur Rev Med Pharmacol Sci. 2018;22(21):7178-7182.

306. Liu N, Zhang J, Zhang LY, Wang L. CircHIPK3 is upregulated and predicts a poor prognosis in epithelial ovarian cancer. Eur Rev Med Pharmacol Sci. 2018;22(12):3713-3718.

307. Chen H, Tian X, Luan Y, Lu H. Downregulated Long Noncoding RNA DGCR5 Acts as a New Promising Biomarker for the Diagnosis and Prognosis of Ovarian Cancer. Technol Cancer Res Treat. 2019;18:1533033819896809.

308. Moes-Sosnowska J, Rzepecka IK, Chodzynska J, et al. Clinical importance of FANCD2, BRIP1, BRCA1, BRCA2 and FANCF expression in ovarian carcinomas. Cancer Biol Ther. 2019;20(6):843-854

309. Zhang XY, Zhou LL, Jiao Y, et al. Adenylate kinase 7 is a prognostic indicator of overall survival in ovarian cancer. Medicine (Baltimore). 2021;100(1):e24134

310. Coussens LM, Werb Z. Inflammation and cancer. Nature. 2002;420(6917):860-867.311

311. Zahorec R. Ratio of neutrophil to lymphocyte counts--rapid and simple parameter of systemic inflammation and stress in critically ill. Bratisl Lek Listy. 2001;102(1):5-14.

312. Guthrie GJ, Charles KA, Roxburgh CS, Horgan PG, McMillan DC, Clarke SJ The systemic inflammation-based neutrophil-lymphocyte ratio: experience in patients with cancer. Crit Rev Oncol Hematol. 2013;88(1):218-230.

313. Wang Y, Liu P, Xu Y, et al. Preoperative neutrophil-to-lymphocyte ratio predicts response to first-line platinum-based chemotherapy and prognosis in serous ovarian cancer. Cancer Chemother Pharmacol. 2015;75(2):255-262.

314. Huang QT, Zhou L, Zeng WJ, et al. Prognostic Significance of Neutrophil-to-Lymphocyte Ratio in Ovarian Cancer: A Systematic Review and Meta-Analysis of Observational Studies. Cell Physiol Biochem. 2017;41(6):2411-2418

315. Mallappa S, Sinha A, Gupta S, Chadwick SJ. Preoperative neutrophil to lymphocyte ratio $>5$ is a prognostic factor for recurrent colorectal cancer. Colorectal Dis. 2013;15(3):323-328.

316. Zhang H, Huo Q, Huang L, Cheng Y, Liu Y, Bao H. Neutrophil-to-Lymphocyte Ratio in Ovarian Cancer Patients with Low CA125 Concentration. Biomed Res Int. 2019;2019:8107906.

317. Bhattacharya B, Mohd Omar MF, Soong R. The Warburg effect and drug resistance. Br J Pharmacol. 2016;173(6):970-979.

318. Deme D, Telekes A. A laktátdehidrogenáz $(\mathrm{LDH})$ prognosztikai jelentősége az onkol ó gi á ban [Prognostic importance of lactate dehydrogenase (LDH) in oncology]. Orv Hetil. 2017;158(50):1977-1988.

319. Xiang J, Zhou L, Zhuang Y, et al. Lactate dehydrogenase is correlated with clinical stage and grade and is downregulated by si-SA T B1 in ovarian cancer. Oncol Rep. 2018;40(5):2788-2797.

320. Valvona CJ, Fillmore HL, Nunn PB, Pilkington GJ. The Regulation and Function of Lactate Dehydrogenase A: Therapeutic Potential in Brain Tumor. Brain Pathol. 2016;26(1):3-17.

321. Miao P, Sheng S, Sun X, Liu J, Huang G. Lactate dehydrogenase A in cancer: a promising target for diagnosis and therapy. IUBMB Life. 2013;65(11):904-910.

322. Chang K, Pastan I. Molecular cloning of mesothelin, a differentiation antigen present on mesothelium, mesotheliomas, and ovarian cancers. Proc Natl Acad Sci US A. 1996:93(1):136-140.

323. He $\mathrm{X}$, Wang L, Riedel $\mathrm{H}$, et al. Mesothelin promotes epithelial-to-mesenchymal transition and tumorigenicity of human lung cancer and mesothelioma cells. Mol Cancer. 2017;16(1):63.

324. Coelho R, Marcos-Silva L, Ricardo S, et al. Peritoneal dissemination of ovarian cancer: role of MUC16-mesothelin interaction and implications for treatment. Expert Rev Anticancer Ther. 2018;18(2):177-186.
325. Chang MC, Chen CA, Chen PJ, et al. Mesothelin enhances invasion of ovarian cancer by inducing MMP-7 through MAPK/ERK and JNK pathways. Biochem J. 2012;442(2):293-302.

326. Yan M, Wang C, He B, et al. Aurora-A Kinase: A Potent Oncogene and Target for Cancer Therapy. Med Res Rev. 2016;36(6):1036-1079.

327. Liu Q, Kaneko S, Yang L, et al. Mitotic kinase Aurora-A phosphorylation and inactivation of p53. Cancer Research. 2004, 64.

328. Lentini L, Amato A, Schillaci T, Di Leonardo A. Simultaneous Aurora-A/STK15 overexpression and centrosome amplification induce chromosomal instability in tumour cells with a MIN phenotype. BMC Cancer. 2007:7:212.

329. Matulonis UA, Sharma S, Ghamande S, et al. Phase II study of MLN8237 (alisertib), an investigational Aurora A kinase inhibitor, in patients with platinum-resistant or -refractory epithelial ovarian, fallopian tube, or primary peritoneal carcinoma. Gynecol Oncol. 2012;127(1):63-69.

330. Thijssen VL, Heusschen R, Caers J, Griffioen AW. Galectin expression in cancer diagnosis and prognosis: A systematic review. Biochim Biophys Acta. 2015;1855(2):235-247.

331. Schulz H, Kuhn C, Hofmann S, et al. Overall Survival of Ovarian Cancer Patients Is Determined by Expression of Galectins-8 and -9. Int J Mol Sci. 2018;19(1):323.

332. Nagahara K, Arikawa T, Oomizu S, et al. Galectin-9 increases Tim-3+ dendritic cells and CD8+ T cells and enhances antitumor immunity via galectin-9-Tim-3 interactions. Journal of Immunology. 2008, 181(11):7660-7669.

333. Bidon-Wagner N, Le Pennec JP. Human galectin-8 isoforms and cancer. Glycoconj J. 2002;19(7-9):557-563.

334. Viallard C, Larriv ée B. Tumor angiogenesis and vascular normalization: alternative therapeutic targets. Angiogenesis. 2017;20(4):409-426.

335. Carmeliet P. VEGF as a key mediator of angiogenesis in cancer. Oncology. 2005;69 Suppl 3:4-10

336. Matsumoto K, Ema M. Roles of VEGF-A signalling in development, regeneration, and tumours. J Biochem. 2014;156(1):1-10.

337. Mishra S, Yadav T, Rani V. Exploring miRNA based approaches in cancer diagnostics and therapeutics. Crit Rev Oncol Hematol. 2016;98:12-23.

338. Meng F, Henson R, Lang M, et al. Involvement of human micro-RNA in growth and response to chemotherapy in human cholangiocarcinoma cell lines. Gastroenterology. 2006;130(7):2113-2129.

339. Peter ME. Targeting of mRNAs by multiple miRNAs: the next step. Oncogene. 2010;29(15):2161-2164

340. Naishadham D. Cancer statistics, 2012. Ca A Cancer Journal for Clinicians. 2015;63(1):11.

341. Chung TK, Cheung TH, Huen NY, et al. Dysregulated microRNAs and their predicted targets associated with endometrioid endometrial adenocarcinoma in Hong Kong women. Int J Cancer. 2009;124(6):1358-1365.

342. Gregory PA, Bert AG, Paterson EL, et al. The miR-200 family and miR-205 regulate epithelial to mesenchymal transition by targeting ZEB1 and SIP1. Nat Cell Biol. 2008;10(5):593-601

343. Sato $\mathrm{E}$, Olson $\mathrm{SH}$, Ahn $\mathrm{J}$, et al. Intraepithelial CD8+ tumor-infiltrating lymphocytes and a high $\mathrm{CD} 8+/$ regulatory $\mathrm{T}$ cell ratio are associated with favorable prognosis in ovarian cancer. Proc Natl Acad Sci U S A. 2005;102(51):18538-18543

344. Hamanishi J, Mandai M, Iwasaki M, et al. Programmed cell death 1 ligand 1 and tumor-infiltrating CD8+ T lymphocytes are prognostic factors of human ovarian cancer. Proc Natl Acad Sci U S A. 2007;104(9):3360-3365.

345. Clemente CG, Mihm MC Jr, Bufalino R, Zurrida S, Collini P, Cascinelli N. Prognostic value of tumor infiltrating lymphocytes in the vertical growth phase of primary cutaneous melanoma. Cancer. 1996;77(7):1303-1310.

346. Pagès F, Galon J, Dieu-Nosjean MC, Tartour E, Sautès-Fridman C, Fridman WH. Immune infiltration in human tumors: a prognostic factor that should not be ignored. Oncogene. 2010;29(8):1093-1102.

347. Santoiemma PP, Powell DJ Jr. Tumor infiltrating lymphocytes in ovarian cancer. Cancer Biol Ther. 2015;16(6):807-820.

348. Tuthill RJ, Unger JM, Liu PY, Flaherty LE, Sondak VK; Southwest Oncology Group. Risk assessment in localized primary cutaneous melanoma: a Southwest Oncology Group study evaluating nine factors and a test of the Clark logistic regression prediction model. Am J Clin Pathol. 2002;118(4):504-511

349. Zhang L, Conejo-Garcia JR, Katsaros D, et al. Intratumoral T cells, recurrence, and survival in epithelial ovarian cancer. N Engl J Med. 2003;348(3):203-213.

350. Turner TB, Buchsbaum DJ, Straughn JM Jr, Randall TD, Arend RC. Ovarian cancer and the immune system - The role of targeted therapies. Gynecol Oncol. 2016;142(2):349-356.

351. Miao L, St Clair DK. Regulation of superoxide dismutase genes: implications in disease. Free Radic Biol Med. 2009;47(4):344-356.

352. Bartling TR, Subbaram S, Clark RR, Chandrasekaran A, Kar S, Melendez JA. Redox-sensitive gene-regulatory events controlling aberrant matrix metalloproteinase-1 expression. Free Radic Biol Med. 2014;74:99-107.

353. Cui Y, She K, Tian D, Zhang P, Xin X. miR-146a Inhibits Proliferation and Enhances Chemosensitivity in Epithelial Ovarian Cancer via Reduction of SOD2. Oncol Res. 2016;23(6):275-282

354. Chang B, Yang H, Jiao Y, et al. SOD2 deregulation enhances migration, invasion and has poor prognosis in salivary adenoid cystic carcinoma. Sci Rep. 2016;6:25918. 
355. Xu Z, Chen Y, Gu D, et al. SOD2 rs4880 CT/CC genotype predicts poor survival for Chinese gastric cancer patients received platinum and fluorouracil based adjuvant chemotherapy. Am J Transl Res. 2015;7(2):401-410.

356. Isono $\mathrm{T}$, Chano $\mathrm{T}$, Yonese J, Yuasa $\mathrm{T}$. Therapeutic inhibition of mitochondrial function induces cell death in starvation-resistant renal cell carcinomas. Sci Rep. 2016;6:25669.

357. Kanwal R, Gupta K, Gupta S. Cancer epigenetics: an introduction. Methods Mol Biol. 2015;1238:3-25.

358. Huang RL, Chen HJ, Chen LY, et al. Epigenetic loss of heparan sulfate 3-O-sulfation sensitizes ovarian carcinoma to oncogenic signals and predicts prognosis. Int J Cancer. 2018;143(8):1943-1953.

359. Bhan A, Soleimani M, Mandal SS. Long Noncoding RNA and Cancer: A New Paradigm. Cancer Res. 2017;77(15):3965-3981. 